\title{
The consequences for stream water quality of long-term changes in landscape patterns: Implications for land use management and policies
}

\author{
António Carlos Pinheiro Fernandes ${ }^{a, *}$, Lisa Maria de Oliveira Martins a , \\ Fernando António Leal Pacheco ${ }^{\mathrm{b}}$, Luís Filipe Sanches Fernandes ${ }^{\mathrm{a}}$ \\ ${ }^{a}$ CITAB - Centre for the Research and Technology of Agro-Environment and Biological Sciences, University of Trás-os-Montes and Alto Douro, Ap. 1013, Vila Real 5001- \\ 801, Portugal \\ ${ }^{\mathrm{b}}$ Chemistry Research Centre, University of Trás-os-Montes and Alto Douro, Ap. 1013, Vila Real 5001-801, Portugal
}

\section{A R T I C L E I N F O}

\section{Keywords:}

Landscape metrics

Water quality

Land-use changes

Urbanised catchment

Ave river basin

Spearman's rank correlation coefficient

Intervention

\begin{abstract}
A B S T R A C T
The preservation of water resources is a worldwide goal that requires continuous research to support the action of decision-makers. The learning about water quality is paramount in that regard to assess the complex interactions between surface waters and pollution sources. To assess the impact of diffuse pressures, many authors established nexus between landscape metrics and surface water quality. The present study used that approach in a Portuguese urban catchment, the Ave River Basin. The relation between landscape metrics and eight surface water quality parameters was studied during 26 hydrological years, based on the Spearman's rank correlation analysis. The correlation analysis exposed strong relationships between water quality and parameters that describe land use composition or configuration. During the studied period, even in recent years, the water quality parameters reached concentrations above the legally recommended limits. The most concerning parameters were ammoniacal nitrogen, chemical oxygen demand and total orthophosphate. Among the analysed metrics, Shannon's diversity index, percentage of urban areas, and the percentage of agricultural edges that are shared with artificial areas were the most preoccupying land use characteristics that indicate degradation of water resources. Besides the correlations, the study calculated the variation rates of land use maps relative to the years of 1995 , 2007, 2010, 2015 and 2018. The results of correlation analysis and land use changes identified actions for the short-term that could improve water quality in the Ave River, namely a reduction in agricultural fields and an increase of forest edges density. In the long-term, water quality improvements could be accomplished through the decrease of artificial surfaces, the increase of forested areas and edges surrounding agricultural fields.
\end{abstract}

\section{Introduction}

The management of freshwater resources to ensure water security concerns civilisations for thousands of years (Dellapenna and Gupta, 2009). With the demographic expansion, threats to stream water quality and availability grew rapidly, becoming a present-day challenge for global water governance (Wiek and Larson, 2012). Environmental and hydrological research provides subsides to water resources managers through monitoring (Bartram, 1996) and the discovering of innovative treatment and remediation techniques (Sharma and Sanghi, 2012). However, a continuous research on the interactions between pollution sources and their impacts on stream water quality is a necessity to understand and control new agents of contamination such as antibiotics or microplastics (Sousa et al., 2020, 2019). The interactions between pollution sources, contaminants and ecosystems are quite complex given their dependence on a multiplicity of sources (Tran et al., 2019) as well as on numerous physicochemical and biological processes (Larsen et al., 2019; Long, 2020; Vannote et al., 1980), the geological influence (Martins et al., 2019), among other factors. Point source pressures are the most evident threats to water quality because they represent direct discharges into surface water bodies (Bolinches et al., 2020). In general, they comprise effluent discharges from urban and industrial activities. Urban effluents are discharged into streams and lakes with high concentrations of organic compounds (Eom and Park, 2021; Hayet et al., 2016). The composition of industrial effluents is highly variable, being heavily concentrated in metals when sourced from mining (Yan et al., 2021), metallurgic (Kang et al., 2016) or textile (Swarnkumar Reddy and Osborne, 2020) industries, or inorganic matter and salts when

\footnotetext{
* Correspondence to: Quinta de Prados, Ed. dos Blocos Laboratoriais Sala C1.10, $1^{\circ}$ Piso, 5000-801 Vila Real, Portugal.

E-mail address: acpf91@utad.pt (A.C.P. Fernandes).
} 
(A)

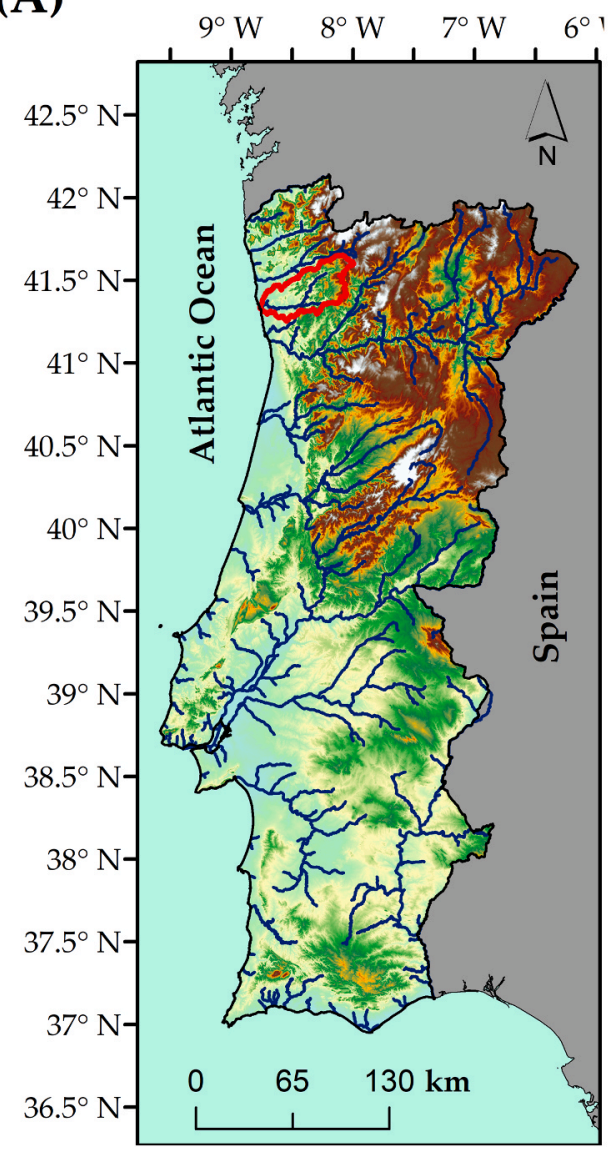

(B)
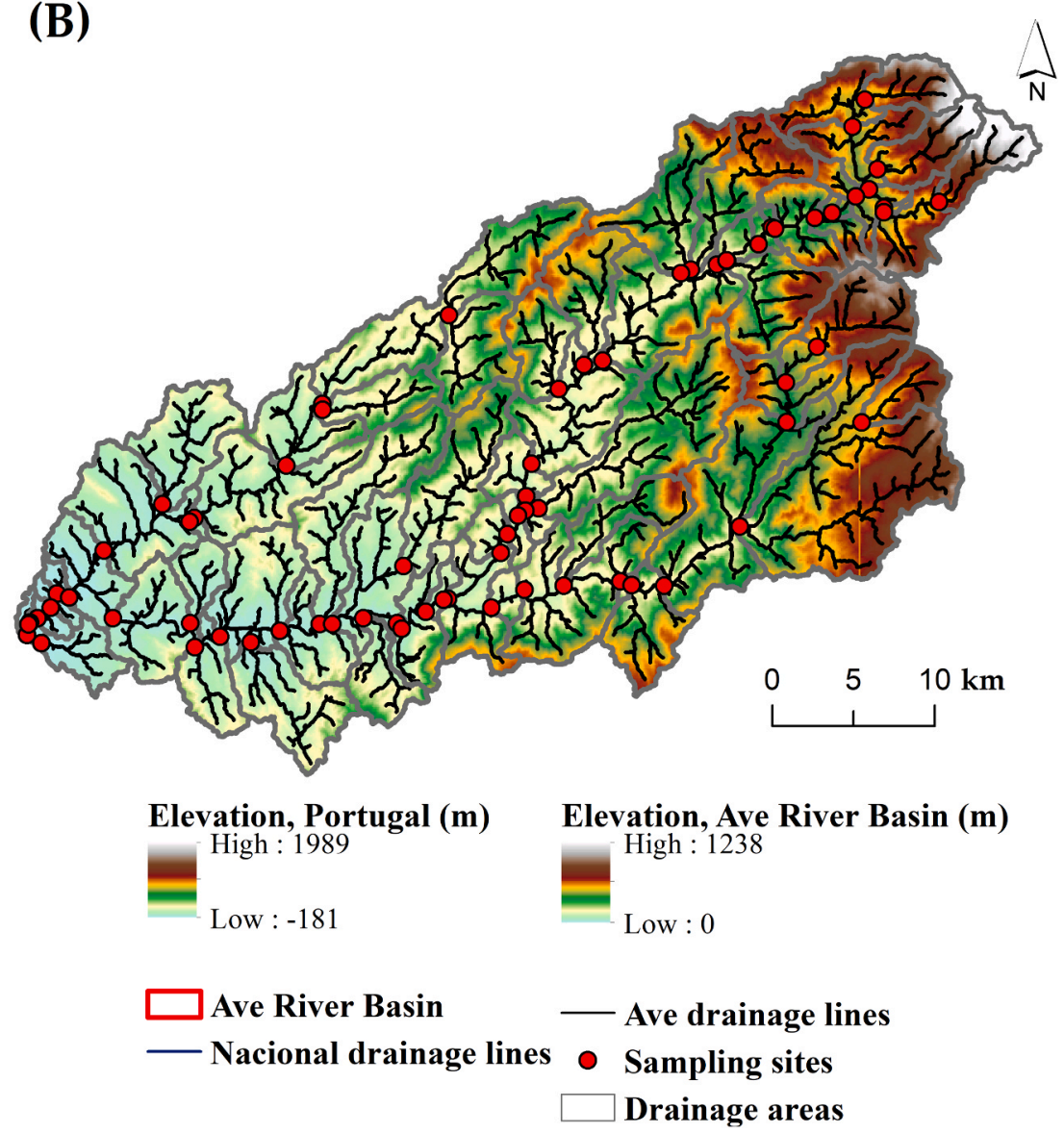

Fig. 1. Ave River Basin. In (A) is represented Portugal and the national drainage lines. In (B) it is demonstrated the Ave River Basin and local drainage lines.

sourced from pharmaceutical industries (Lalwani et al., 2020). Diffuse pressures are less apparent because contaminants need to be transported from the soil surface via runoff before they enter the natural aquatic system (Mohamadi and Kavian, 2015). But their influence is usually dominant. In the last decade of 20th century, non-point pollution sources were responsible for $70 \%$ of stream water contamination in the Southern region of the USA (Potter et al., 2005). There is a plethora of diffuse pressures that can affect surface water quality. Agricultural fields are among the most worrying pressures because fertilisers (Zörb et al., 2014) and pesticides (Jayasumana et al., 2014) applied to grow crops frequently end up in freshwater. A similar condition holds for livestock fields (Martinez et al., 2009), from where a portion of animal excrements are leached to nearby streams. The threat to stream water quality related with agriculture and livestock production also derives from inadequate land management that frequently exposes the soil, making it proner to erosion and a source of suspended materials that can enter stream water increasing turbidity (Madsen et al., 2001) and endangering aquaic life in the sequel. For similar reasons, wildfires are a threat to stream water quality. In this case, the threat relates with ash transport (Santos et al., 2015a) and amplified erosion of burnt areas (Santos et al., 2015b).

When forested areas are strategically located, for example, along stream margins, they can work as barriers to retain contaminants and sediments transported in runoff (Nilsson and Svedmark, 2002). The conservation of riparian vegetation is therefore paramount for the protection of rivers (Tabacchi et al., 2000). But surface water quality depends on land use planning in general (Foley et al., 2005). Many authors understood this dependence and conducted studies to expand their knowledge on the ties between land use and water quality, especially after 1970 (Zhao et al., 2011). These studies recognised agricultural areas and artificial surfaces to have a negative impact on surface waters, as expected (Gu et al., 2019; Lee et al., 2009; Lenat and Crawford, 1994; Shi et al., 2017; White and Greer, 2006; Yong and Chen, 2002). As mentioned above, agricultural areas are sources of fertilizers and pesticides at the landscape level, that leach towards water bodies in response to storm events, while the expected growth of fertiliser and pesticide use is thought to aggravate stream water quality problems in the future (Wei et al., 2020). The areas occupied with forests, on the other hand, were seen as reserves of good quality water (Clément et al., 2017), with no surprise. Finally, the urban and industrial areas, given the abundance of impervious surfaces that reduce infiltration (Zhang et al., 2020), tend to accumulate contaminants at the ground surface during the dry seasons and drain them to storm sewers and the natural environment during the subsequent rainy periods (Wei et al., 2020). Therefore, land use composition and configuration are linked to water quality (Uuemaa et al., 2007). It is worth recalling at this point the concept of "composition" that describes how much of a landscape is occupied by a land use type (i.e., the area), while "configuration" describes the distribution and arrangement of land uses (Tolessa et al., 2016). These properties are measured through landscape metrics, which are indexes used to quantify landscape characteristics. There is a wide range of landscape metrics, such as patch density, Shannon's diversity index (SHDI), edge density, which can be calculated using computer packages such as Fragstats software (McGarigal and Marks, 1995). Within the scope of water quality, landscape affects the influence of non-point pollution sources (Zhang et al., 2018), because landscape structure is the main factor controlling contaminant transference through the runoff mechanism (Uuemaa et al., 2007), considering the different land use types, imperviousness ratios, and released contaminants (Wei et al., 2020; Zhang et al., 2020). Various studies set up nexus between anthropogenic activity, increases of edge density (Lee et al., 


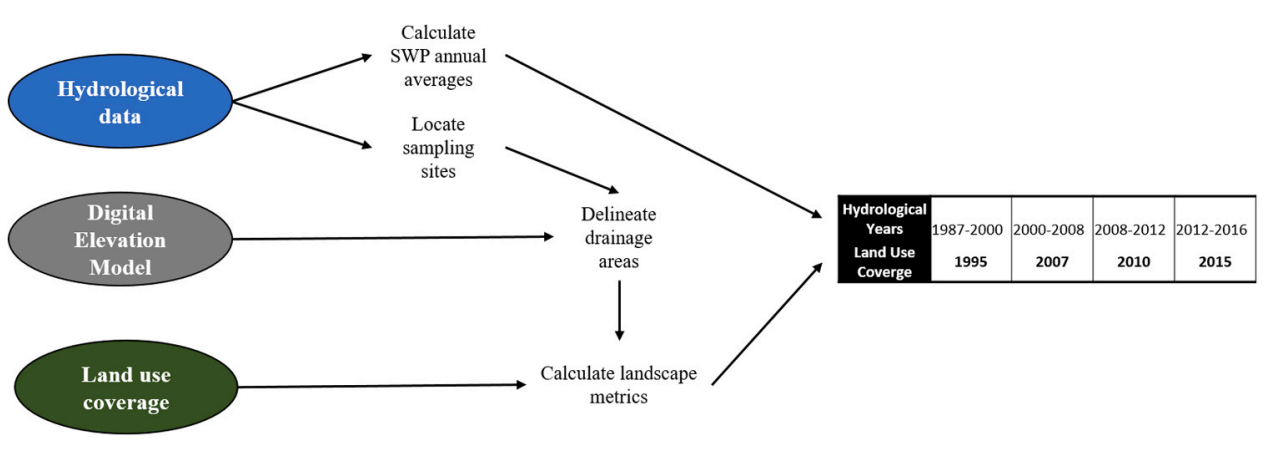

Fig. 2. Dataset preparation.

2009) and hence of SHDI increases (Bu et al., 2014; Sun et al., 2013), with the decrease of water quality (Łowicki, 2012). Other studies have correlated the patch index and patch density with surface water quality (Ding et al., 2016; Shi et al., 2017), showing the loss of filtering capacity of fragmented forests relative to non-fragmented forests (Lee et al., 2009). However, there is a debate about the suitable scale to use, because the relation between landscape and water quality may change with the adopted scale (Zhang et al., 2018). The scale can range from entire catchments, circular buffers, or riparian extents (Allan et al., 1997; Morley and Karr, 2002). Some authors defend that a riparian scale provides better results since it catches all phenomena that are closeby to rivers (Dodds and Oakes, 2008; Johnson et al., 1997; Tran et al., 2010). Other authors contend that entire catchments should be used to reveal all phenomena that occur in the river basin (Hunsaker and Levine, 1995; Zhang et al., 2019). The debate extends to the factors of discrepancy. Some studies point to differences between environmental settings that may interfer with the landscape - water quality nexus (Gu et al., 2019), namely differences in topography (Yu et al., 2016), hydrology or climate (Zhang et al., 2019). Topography influences diffuse emissions because from steeper regions the runoff is faster (Gu et al., 2019) increasing the risk of contaminants being transported to rivers (Bonansea et al., 2021). Precipitation patterns regulate runoff intensity in the spatial domain, while this variable can vary considerably in the short- (season) and long(climate change) terms of time (Nobre et al., 2020). This may help explaining discrepancies between results obtained in the wet and dry seasons as well as in different years and regions (Bonansea et al., 2021; Buonocore et al., 2021; Pak et al., 2021; Shehab et al., 2021). Other causes of discrepancy can be instrumental, related with the spatial resolution of land use and cover maps (Wu et al., 2002), or with the study design (Schiff and Benoit, 2007).

Despite the multiplicity of factors influencing the relationship between water quality and landscapes, the number of studies addressing these factors simultaneously is scarce. From a land use management and policy viewpoint, holistic studies of this kind are helpful for the panoramic understanding they provide about stream water quality and bearing factors. With the purpose of contributing to fill this gap, the present study analysed the relationship between water quality and landscape metrics in a heterogeneous river basin of Portugal, to capture the influences of a diversity of land use types, namely agriculture, forest occupation and artificial surfaces. The correlations involved 8 water quality parameters pertinent for agriculture as well as urban and industrial contamination, and 61 landscape metrics of composition and configuration. The number of measurement points were 52 with drainage areas spanning a large range $\left(26.4-2475.3 \mathrm{~km}^{2}\right.$ ). The study covered 26 hydrologic years to detect potential climate effects. Taken altogether, we believe the results of this "brute-force" study involving over 13,000 correlations will help to understand how composition and structure of watersheds determines stream water quality, considering the roles of environmental settings (climate, land use types) and scale.

\section{Study area}

In the present study, it was explored the relationship between surface water parameters and landscape metrics in an industrialised Portuguese river basin over many hydrological years, resorting to the Spearman correlation rank coefficient. Ave River Basin (ARB) is located in the northern region of Portugal, Fig. 1. The Ave river extends for $100 \mathrm{~km}$ from the headwaters located in the Cabreira mountains until the outlet for the Atlantic Ocean. The drainage area occupies around $1400 \mathrm{~km}^{2}$, and the main tributaries are Vizela and Este rivers, with drainage areas that hold $323 \mathrm{~km}^{2}$ and $250 \mathrm{~km}^{2}$, respectively. The altitude varies from $1254 \mathrm{~m}$ at the headwaters to $0 \mathrm{~m}$ at the Atlantic Coast. This river basin was chosen for this study due to the vast contamination problems that started almost a hundred years ago. Already in the first half of the 20th century, many pollution transgressions were reported to local authorities (Costa, 2008). In the second half of the 20th century, the river was tagged as "The Great Sewer" (Ferreira et al., 2017) due to the high number of effluent discharges without any preliminary treatment, mainly from textile industries and domestic sewage (Cortes et al., 2016). So it became one of the most polluted in Europe, which has caught the attention of several researchers. Until nowadays, the river basin has been a target of many environmental studies.

In pioneer studies, high concentrations of heavy metals were found in river sediments and aquatic mosses due to industrial activities, by accessing data from 1993 (Gonçalves et al., 1992; Soares et al., 1999). Besides Araújo et al. (1998) revealed that a high concentration of metals was due to the local lithology, but the presence of heavy metals was due to anthropogenic activity. Due to an ambitious remediation program, heavy metal pollution has fortunately decreased in 2000 (Alves et al., 2009). Despite the given importance to heavy metals, other authors aimed their studies at other forms of contamination, namely nutrients. By assessing the leaf breakdown (Pascoal et al., 2003) between 1999 and 2000, ARB had high levels of nutrients that were compromising the freshwaters status (Pascoal et al., 2005a). In the Este river, it was possible to trace a high diversity of aquatic hyphomycetes, but in the Ave river, there was a decline of species richness (Pascoal et al., 2005b). The declared causes were the high agricultural activity and also effluent discharges. In concordance, other authors refer to the same pollution causes (Dunck et al., 2015; Peixoto et al., 2013), but also livestock production effects became concerning (Ribeiro et al., 2016), which led authors to give more attention to the impacts of diffuse pollution sources (Fonseca et al., 2018; Terêncio et al., 2017). In studies where the effects of diffuse and point source pressures are accessed, the results show both have a massive effect (Fernandes et al., 2019, 2018). Still, in those studies, the impact of the land-use configuration was not accessed.

In subsequent studies, landscape structure was compared to estimated diffuse and point source emissions, and it was found out that landscape effects can overcome contaminant emissions (Fernandes et al., 2019a) depending on the analysed scale (Fernandes et al., 2020). In the present study is investigated the effect of landscape characteristics (LSC) on water quality due to human activity and expose which 
Table 1

Landscape metrics list.

\begin{tabular}{|c|c|c|c|c|c|c|c|c|}
\hline \multirow[b]{2}{*}{ Group } & \multirow{2}{*}{ Nomenclature } & \multirow{2}{*}{ Description } & \multirow{2}{*}{ Units } & \multicolumn{5}{|c|}{ Land use Classes } \\
\hline & & & & $\vec{z}$ & 递 & 选 & ơ & $\overbrace{3}^{\infty}$ \\
\hline \multirow{3}{*}{ Area } & ca & total area & $\mathrm{km}^{2}$ & & $x$ & $\mathrm{x}$ & $x$ & $\mathrm{x}$ \\
\hline & $\mathrm{npc}$ & number of patches & count & & $\mathrm{x}$ & $\mathrm{x}$ & $\mathrm{x}$ & $\mathrm{x}$ \\
\hline & $\mathrm{pz}$ & area percentage & $\mathrm{km}^{2} / \mathrm{km}^{2}$ & & $\mathrm{x}$ & $\mathrm{x}$ & $\mathrm{x}$ & $\mathrm{x}$ \\
\hline \multirow{2}{*}{ Edge } & tc_edge & length of edges of all patches in selected classes within the statistical zone & meters & $x$ & $x$ & $x$ & $x$ & $\mathrm{x}$ \\
\hline & ed & edge density & $\mathrm{km}^{2} /$ hectare & $x$ & $\mathrm{x}$ & $\mathrm{x}$ & $x$ & $\mathrm{x}$ \\
\hline Diversity & shdi & Shannon's diversity index (SHDI) & & $\mathrm{x}$ & & & & \\
\hline \multirow{2}{*}{ Contrast } & el & total edge length shared between the two selected land use classes & $\mathrm{km}$ & & $\mathrm{x}$ & $\mathrm{x}$ & $\mathrm{x}$ & $x$ \\
\hline & cce & percentage of the edge length shared between the two selected land use classes & $\mathrm{km}^{2} / \mathrm{km}^{2}$ & & $\mathrm{x}$ & $\mathrm{x}$ & $\mathrm{x}$ & $\mathrm{x}$ \\
\hline \multirow{5}{*}{ Connectance } & ci_np & number of connected patches & count & & $\mathrm{x}$ & $\mathrm{x}$ & $\mathrm{x}$ & $\mathrm{x}$ \\
\hline & ci_pa & patch area within the range of connection & $\mathrm{km}^{2}$ & & $x$ & $x$ & $\mathrm{x}$ & $x$ \\
\hline & ci_pp & percentage of patch area within the range of connection & $\mathrm{km}^{2} / \mathrm{km}^{2}$ & & $\mathrm{x}$ & $\mathrm{x}$ & $x$ & $x$ \\
\hline & ci_ca & area of the connection polygons between patches & $\mathrm{km}^{2}$ & & $x$ & $x$ & $x$ & $x$ \\
\hline & ci_cp & percentage of the area of the connection polygons between patches & $\mathrm{km}^{2} / \mathrm{km}^{2}$ & & $\mathrm{x}$ & $\mathrm{x}$ & $\mathrm{x}$ & $\mathrm{x}$ \\
\hline
\end{tabular}

characteristics require intervention. In this analysis, it was calculated the Spearman's Rank Correlation Coefficient, between landscape metrics (LSM) and surface water parameters (SWP) for different hydrological years (HYs), and make an intervention analysis to tag which are the possible LSC that require intervention.

\section{Methodology}

\subsection{Dataset preparation}

For the dataset preparation, it was necessary to resort to three databases, which contained hydrological data, the digital elevation model and a land cover, Fig. 2. The accessed hydrological database was the National Hydrological Information System (the Portuguese abbreviation is SNIRH) (Jesus et al., 1999). The digital elevation model was downloaded from the European Environmental Agency (EEA, 2021) with a resolution of $25 \mathrm{~m}$ and was used to delineate the drainage areas. The land use cover map was download from the Portuguese Territory Planning website (DGT, 2018), whose coverage was available for the years of 1995, 2007, 2010, 2015 and 2018.

From SNIRH, it was downloaded all the information about surface water parameters that had data for an extended period (from 1987 to 2016). For each of the SWP in each sampling site (Fig. 1), it was calculated the average concentration for each hydrological year (HY), starting on the 1st of October and ending on the 30th of September. With the location of sampling sites and the digital elevation model, it was possible to delineate the entire watershed, drainage lines and respective drainage areas of each sampling site. All these procedures were executed in ArcMap (ESRI, 2012a) using ArcHYDRO functionalities (ESRI, 2012b). With the delineated drainage area, it was possible to calculate the landscape metrics using each land use map. The metrics were calculated by using a python toolbox (Adamczyk and Tiede, 2017) for the general land use classes: agricultural areas (AGR), artificial surfaces (ART), forests and semi-natural areas (FOR) and water bodies (WAB). The complete list of landscape metrics is demonstrated in Table 1, in the description is given the measured LSC. The calculated metrics are divided into five groups: area, edge, diversity, contrast and connectance. Area metrics describe the proportion of land use in each drainage area, ca is the total area of the respective land use, pz the area proportion and npc the number of patches. Edge metrics are calculated based on the perimeter of patches for the selected land use, tc_edge the total length and ed is the same length divided by the total area. Diversity metrics only contain shdi, a diversity index calculated for all land use classes, named in this study as shdi_(ALL). Contrast metrics describe the length of land use patches that are shared between two selected land use classes, where el_( $\left(\mathrm{LU}_{\mathrm{A}}\right)_{-}$with_( $\left(\mathrm{LU}_{\mathrm{B}}\right)$ is the total length between the classes $\mathrm{A}$ and $\mathrm{B}$, which is the same as el_( $\left(\mathrm{LU}_{\mathrm{B}}\right)_{-}$with_( $\left(\mathrm{LU}_{\mathrm{A}}\right)$, while the percentage of the length of land use edges is calculated through the metric cce. For example, the cce_( $\left(\mathrm{UU}_{\mathrm{A}}\right)_{-}$with_( $\left(\mathrm{LU}_{\mathrm{B}}\right)$ is the edge length shared between land use $A$ and $B$, divided by the total length of edges of $L_{B}$, while cce_( $\left(L_{B}\right)_{-}$with_ $\left(L U_{A}\right)$ is also the length shared between land use $A$ and $\mathrm{B}$, but in this case, is divided by the total length of $\mathrm{LU}_{\mathrm{A}}$ edges. Contrast metrics were calculated for all the possible combinations between WAB, FOR, ART and AGR. Connection metrics describe the connectedness of land use patches for a selected class. For these metrics, the python toolbox calculates the connectedness area for a specified distance, which for this study is $0.5 \mathrm{~km}$. The number of patches that are inside of the connectance range is given by ci_np. The connection area is provided by ci_ca, and the area percentage by ci_cp. The metric ci_pa is the area of the selected land-use class within the range of connection, while ci_pp is the respective area percentage. From a total of thirteen metrics types, it was calculated a total of 61 , since each type was calculated for particular types of land uses or even to all simultaneously, Table 1. Besides there are only 5 Portuguese land use maps, it was assumed that each map was representative of the closest HYs. Therefore, the land use map of 1995 represents the HYs between 1987 and 2000, the map of 2007 represents the HYs between 2000 and 2008, the map of 2010 represents the HYs between 2008 and 2012 and the map of 2015 from 2012 until 2016, Fig. 2. Thereby, it was possible to calculate the Spearman's Rank Correlation Coefficient $\left(r_{s}\right)$ between each landscape metric and surface water parameter for each HY, using python (McKinney, 2015).

In the supplementary material is provided the analysis of the SWP, and also the correlation analysis of the SWP along each HY, while in the results section is demonstrated the $r_{s}$ analysis between each SWP and LSM. Also, the $r_{s}$ values between each LSM and SWP, along each HY, are provided in the supplementary material in an excel worksheet.

\subsection{Analysis}

\subsubsection{Spearman's rank correlation coefficient}

To understand the relationship between each LSM and SWP it was calculated the $r_{s}$ for all the HY. The $r_{s}$ is a non-parametric method (Hauke and Kossowski, 2011) that measures the monotonic relationship between two variables, unlike Pearson's correlation coefficient, does not require certain assumptions such as normal distribution and absence of outliers (Rebekić et al., 2015). Another reason that led the authors to chose Spearman's correlation rank is that this correlation is suitable for 


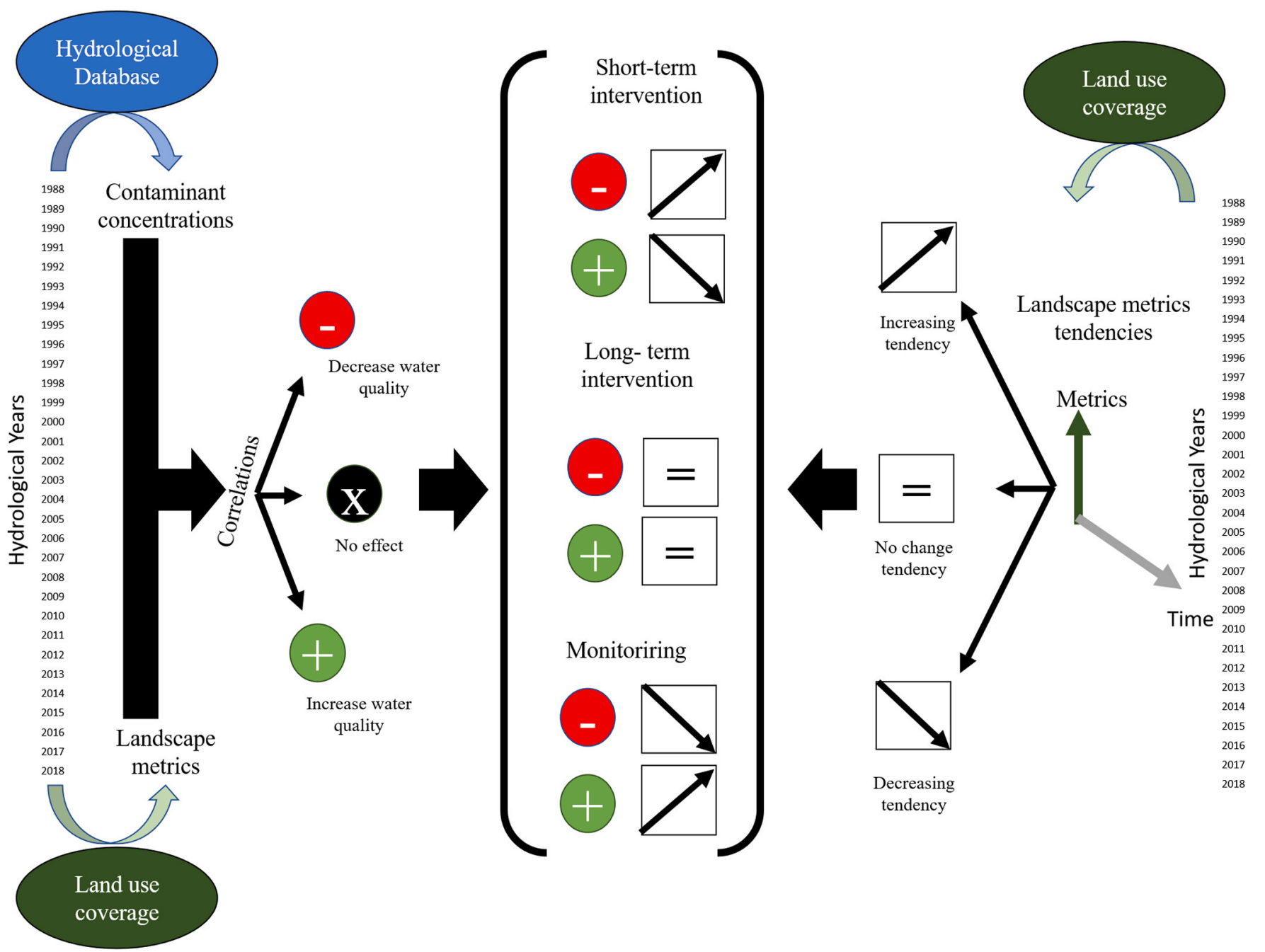

Fig. 3. Analysis procedure.

variables that do not have a linear relationship (Zar, 2005), while Pearson correlation only measures the linear connection between two variables (Hauke and Kossowski, 2011).

\subsubsection{Intervention analysis}

From the Portuguese hydrological database (SNIRH) it was obtained the SWP data, measured in at least five sampling sites in consecutive HY. In total, only eight parameters satisfied this restriction, shown in appendix A, Table A.1. From physical properties, only total suspended solids and conductivity measurements were available. Nutrient concentrations are represented by ammoniacal nitrogen, total nitrate and total orthophosphate. Other parameters related to oxygen availability are biological and chemical oxygen demands and also dissolved oxygen concentration.

To check if a LSC increase/decrease a SWP concentration, it was analysed the statistical significance and sign of the respective $r_{s}$, for each HY. If the $r_{s}$ was positive and statistically significant, it was assumed that the correlated LSC has a negative impact on water quality (WQ), since it increases the contaminant concentration in the analysed HY. While when the correlation was negative and statistically significant, the LSC decreases the concentration. Only the dissolved oxygen analysis had an opposite interpretation of the $r_{s}$ sign since dissolved oxygen is not a contaminant. For the correlations that had non-statistical significance, it was assumed that the LSC did not affect the SWP during the respective HY, as portrayed in Fig. 3. A total of 208 correlations were analysed for each LSM, since the number of SWP is 8 and the number of analysed HYs is 26. For each LSM, if the number of correlations (NOC) that indicated a negative effect (decreasing WQ) was equal or higher to half of the total NOC (104), it was assumed that the LSC decreases WQ in ARB, while if the NOC with a positive effect was higher than 104 it was assumed that the LSC increases WQ in ARB. Through the adopted methodology, it was analysed a total of 12688 correlations between each of the 8 SWP and 61 LSM for 26 HYs.

To understand if a LSC requires intervention, it was made an additional analysis by comparing the NOC with the LSM variation over time. First, for each LSM it was calculated the metric average for each land-use coverage map. Then it was divided the metric value of the most recent land use map (2018) by the average (1997-2015). If the variation was between $-10 \%$ and $10 \%$, it was assumed that the LSC was not changing. While if the variation was higher than $10 \%$, it was considered that the LSM has an increasing tendency, while if the variation was lower than $-10 \%$, it has a decreasing tendency.

By combining the correlations and LSM variation changes, it was possible to trace intervention priorities for each LSC that had an effect on WQ. It was defined a total of three classifications, short-term, long-term and monitoring. The classification as short-term was given for LSC that had an urgent necessity for intervention, which are the ones that have a negative impact on WQ and tendency to increase, and also to the LSC that had a positive impact on WQ and a tendency to decrease. For LSC with a positive or a negative impact but no tendency to increase or decrease, it was attributed to a less urgent priority, long-term. For LSC with a positive effect and a tendency to increase and also for LSC with an 
(A)

2000-2001

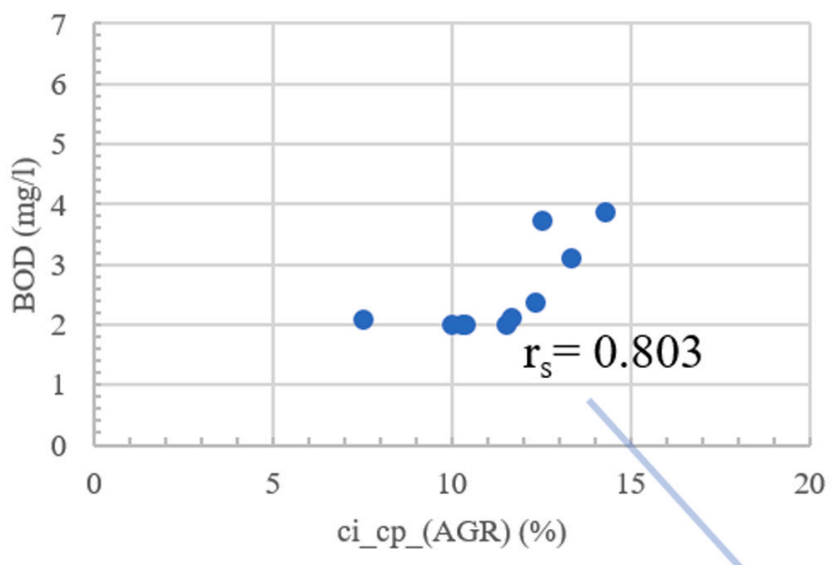

(B)

$2010-2011$

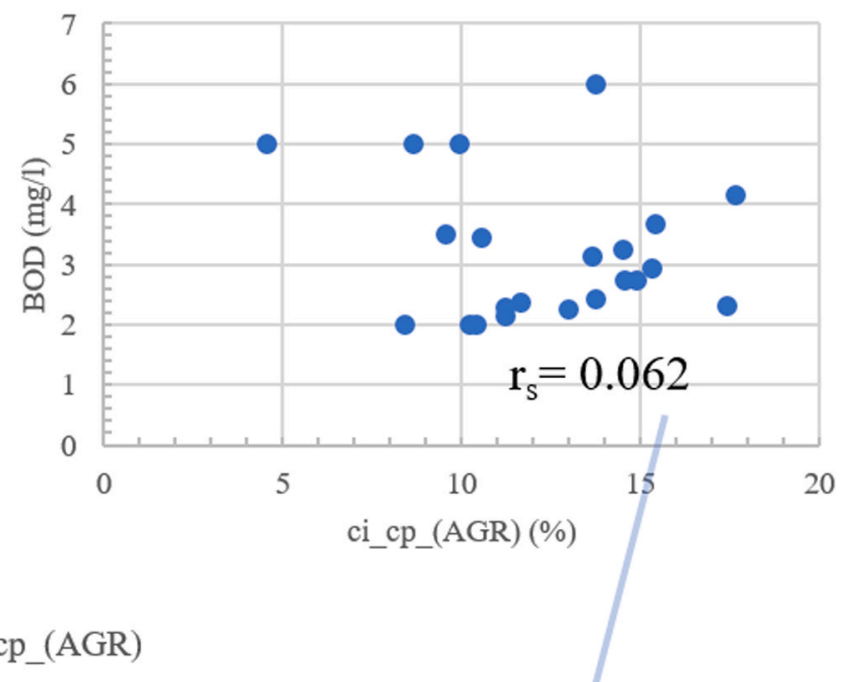

(C)

$\mathrm{r}_{\mathrm{s}}$ BOD vs ci_cp_(AGR)

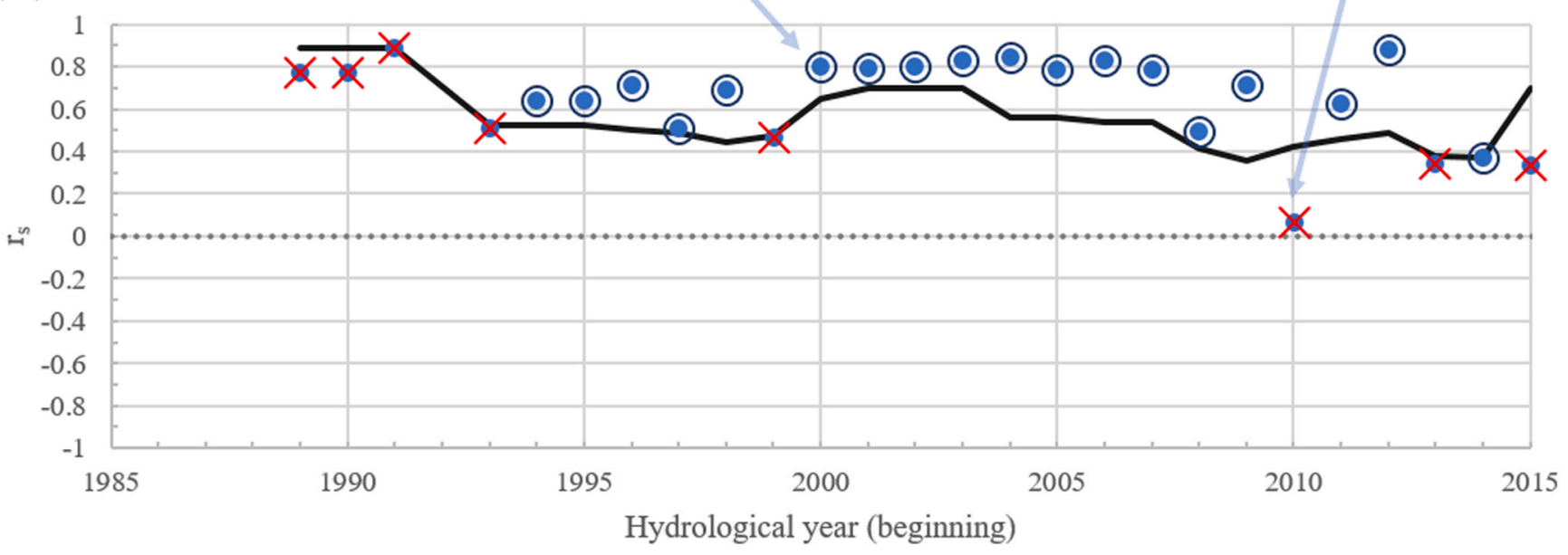

(D)

$\mathrm{r}_{\mathrm{s}}$ BOD vs pz_(FOR)

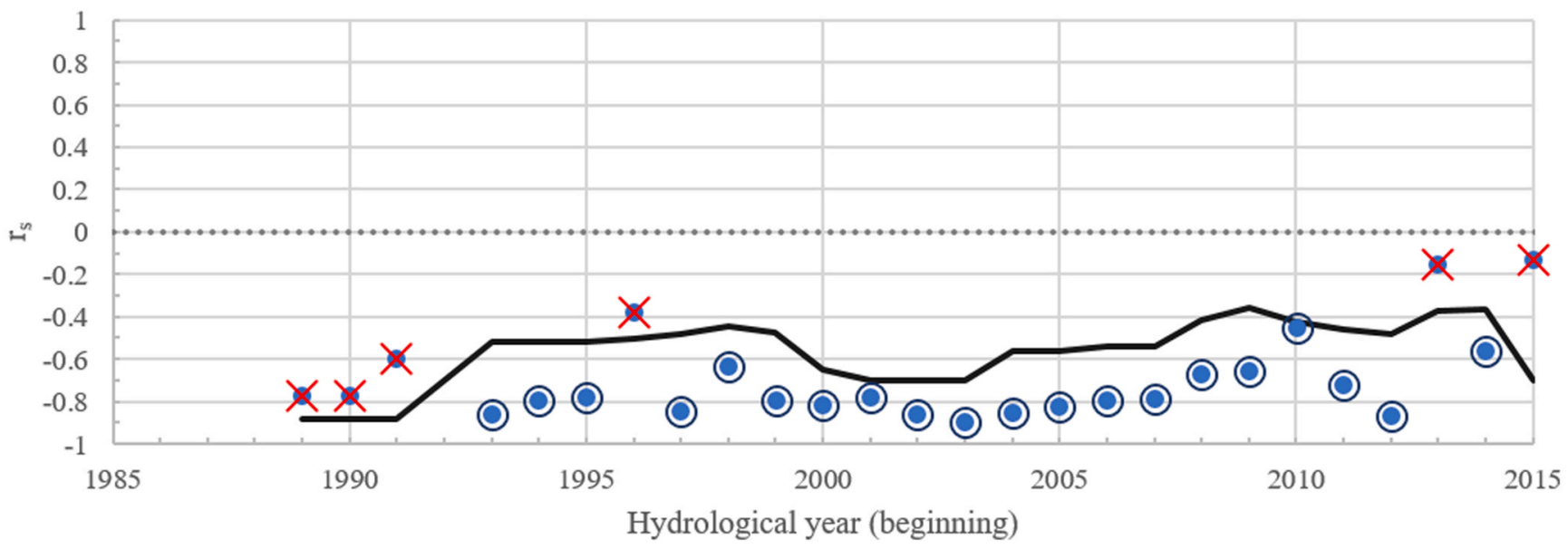

Spearman's Rank Correlation Coefficient $\quad$ Critical Value 0 Significant $\times$ Non significant

Fig. 4. Correlation analysis between BOD and two LSM. (A) Correlation between BOD and ci_cp_(AGR) for the HY 2000-2001. (B) Correlation between BOD and ci_cp_(AGR) for the HY 2010-2011. (C) Correlations between BOD and ci_cp_(AGR) for each HY. (D) Correlations between BOD and pz_(FOR) for each HY. 
Table 2

Number of correlations that indicate the decrease of water quality for each SWP and LSM.

\begin{tabular}{|c|c|c|c|c|c|c|c|c|c|}
\hline$c a_{-}(A G R)-$ & 13 & 23 & 18 & 6 & 17 & 14 & 14 & 13 & \multirow[b]{8}{*}{25} \\
\hline$c a_{-}(\mathrm{ART})-$ & 15 & 23 & 21 & 17 & 20 & 17 & 16 & 16 & \\
\hline $\mathrm{Ca}_{-}(\mathrm{FOR})-$ & 5 & 12 & 10 & 4 & 9 & 5 & 5 & 9 & \\
\hline $\mathrm{Ca}(\mathrm{WAB})$ & 1 & 8 & 6 & 4 & 6 & 3 & 5 & 9 & \\
\hline$n p c_{-}(A G R)$ & 11 & 23 & 19 & 6 & 18 & 12 & 11 & 14 & \\
\hline$n p \bar{c}_{-}(A R T)$ & 13 & 23 & 19 & 10 & 19 & 13 & 14 & 14 & \\
\hline$n p c_{-}(F O R)$ & 5 & 15 & 11 & 4 & 10 & 9 & 6 & 9 & \\
\hline$n p c_{-}(W A B)$ & 1 & 9 & 8 & 4 & 7 & 4 & 5 & 8 & \\
\hline$p z_{-}(A G R)$ & 16 & 20 & 15 & 22 & 20 & 15 & 18 & 9 & \\
\hline $\mathrm{pz} \_(\mathrm{ART})-$ & 17 & 23 & 21 & 23 & 21 & 20 & 19 & 19 & \\
\hline$p z_{-}(F O R)-$ & 0 & 0 & 0 & 0 & 0 & 0 & 0 & 0 & \\
\hline$p z_{-}(W A B)-$ & 2 & 0 & 0 & 0 & 0 & 2 & 1 & 5 & \\
\hline tc_edge_(ALL) & 8 & 22 & 18 & 5 & 11 & 9 & 8 & 12 & \\
\hline tc_edge_(AGR) - & 11 & 23 & 18 & 6 & 17 & 14 & 13 & 14 & \\
\hline tc_edge_(ART) - & 13 & 23 & 19 & 14 & 20 & 17 & 15 & 14 & \\
\hline tc_edge_(FOR) - & 5 & 12 & 10 & 4 & 9 & 5 & 5 & 9 & \\
\hline tc_edge_(WAB) - & 1 & 9 & 7 & 4 & 6 & 3 & 5 & 8 & -20 \\
\hline ed_(ALL) & 9 & 19 & 12 & 12 & 17 & 14 & 11 & 9 & \\
\hline ed_(AGR) - & 16 & 22 & 19 & 25 & 19 & 18 & 17 & 14 & \\
\hline ed_(ART) & 17 & 23 & 20 & 23 & 20 & 19 & 19 & 17 & \\
\hline ed_(FOR) - & 0 & 0 & 0 & 0 & 0 & 0 & 0 & 0 & \\
\hline ed_(WAB) & 2 & 6 & 5 & 3 & 3 & 2 & 5 & 8 & \\
\hline shdi_(ALL) - & 18 & 23 & 21 & 23 & 21 & 20 & 19 & 18 & \\
\hline el_(ART)_with_(AGR) - & 12 & 23 & 19 & 12 & 19 & 15 & 15 & 13 & \\
\hline el_(FOR)_with_(AGR)- & 5 & 18 & 11 & 5 & 11 & 8 & 5 & 11 & \\
\hline el_(WAB)_with_(AGR) - & 4 & 13 & 12 & 4 & 11 & 7 & 8 & 9 & 15 등 \\
\hline el_(FOR)_with_(ART) - & 13 & 23 & 18 & 11 & 19 & 17 & 15 & 13 & 10 음 \\
\hline el_(WAB)_with_(ART) - & 2 & 10 & 7 & 4 & 8 & 5 & 5 & 7 & TO \\
\hline el_(WAB)_with_(FOR)- & 1 & 8 & 6 & 4 & 5 & 2 & 4 & 9 & (1) \\
\hline cce_(ART)_with_(AGR) - & 16 & 23 & 20 & 23 & 23 & 20 & 20 & 18 & $\grave{O}$ \\
\hline cce_(FOR)_with_(AGR)- & 0 & 0 & 0 & 0 & 0 & 0 & 0 & 0 & $\tilde{u}$ \\
\hline cce_(WAB)_with_(AGR) - & 3 & 5 & 5 & 3 & 5 & 4 & 6 & 7 & 4 \\
\hline cce_(AGR)_with_(ART) - & 0 & 0 & 0 & 0 & 0 & 0 & 0 & 0 & $\frac{1}{01}$ \\
\hline cce_(FOR)_with_(ART) - & 0 & 0 & 0 & 0 & 0 & 0 & 0 & 0 & ف \\
\hline cce_(WAB)_with_(ART) - & 2 & 10 & 9 & 4 & 7 & 3 & 7 & 8 & $\varepsilon$ \\
\hline cce_(AGR)_with_(FOR) - & 6 & 7 & 4 & 11 & 2 & 4 & 4 & 1 & 10 ב \\
\hline cce_(ART)_with_(FOR) - & 17 & 22 & 19 & 23 & 19 & 16 & 17 & 15 & Z \\
\hline cce_(WAB)_with_(FOR)- & 3 & 3 & 2 & 1 & 0 & 2 & 1 & 6 & \\
\hline cce_(AGR)_with_(WAB)- & 3 & 2 & 2 & 3 & 0 & 1 & 0 & 0 & \\
\hline cce_(ART)_with_(WAB) & 3 & 10 & 8 & 4 & 8 & 4 & 7 & 7 & \\
\hline cce_(FOR)_with_(WAB)- & 0 & 0 & 0 & 0 & 0 & 0 & 0 & 1 & \\
\hline ci_np_(AGR) - & 9 & 22 & 19 & 7 & 15 & 10 & 10 & 13 & \\
\hline ci_np_(ART) - & 13 & 23 & 20 & 12 & 17 & 13 & 13 & 12 & \\
\hline ci_np_(FOR) - & 13 & 23 & 20 & 15 & 19 & 15 & 15 & 13 & \\
\hline ci_np_(WAB)- & 9 & 22 & 14 & 3 & 19 & 11 & 12 & 14 & 5 \\
\hline ci_pa_(AGR)- & 9 & 22 & 18 & 5 & 13 & 11 & 9 & 14 & \\
\hline ci_pa_(ART) - & 14 & 23 & 20 & 14 & 19 & 17 & 15 & 13 & \\
\hline ci_pa_(FOR) - & 13 & 23 & 18 & 8 & 17 & 13 & 14 & 13 & \\
\hline ci_pa_(WAB) - & 9 & 22 & 14 & 4 & 19 & 11 & 12 & 13 & \\
\hline ci_pp_(AGR) - & 15 & 23 & 22 & 18 & 21 & 20 & 18 & 19 & \\
\hline ci_pp_(ART) - & 15 & 22 & 18 & 25 & 19 & 18 & 17 & 13 & \\
\hline Ci_pp_(FOR) - & 7 & 15 & 7 & 18 & 8 & 5 & 5 & 3 & \\
\hline ci_pp_(WAB)- & 8 & 19 & 13 & 3 & 16 & 9 & 11 & 13 & \\
\hline ci_ca_(AGR) - & 8 & 22 & 17 & 5 & 13 & 12 & 8 & 13 & 0 \\
\hline ci_ca_(ART) - & 14 & 23 & 21 & 14 & 19 & 16 & 15 & 13 & \\
\hline ci_ca_(FOR) - & 12 & 23 & 18 & 7 & 17 & 13 & 13 & 13 & \\
\hline ci_ca_(WAB)- & 9 & 22 & 14 & 4 & 19 & 11 & 12 & 13 & \\
\hline Ci_cp_(AGR) - & 14 & 23 & 20 & 12 & 20 & 18 & 18 & 15 & \\
\hline ci_cp_(ART) - & 15 & 22 & 17 & 24 & 19 & 18 & 17 & 12 & \\
\hline Ci_cP_(FOR) - & 15 & 22 & 13 & 22 & 15 & 9 & 10 & 6 & \\
\hline ci_cp_(WAB) - & 8 & 22 & 14 & 4 & 19 & 11 & 13 & 13 & \\
\hline & 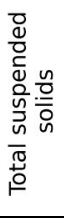 & 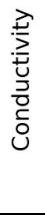 & 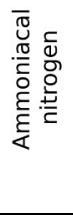 & 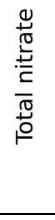 & 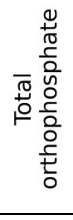 & 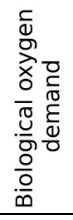 & 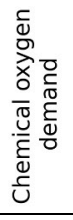 & 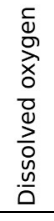 & \\
\hline
\end{tabular}


Table 3

Number of correlations that indicate the increase of water quality for each SWP and LSM.

\begin{tabular}{|c|c|c|c|c|c|c|c|c|c|}
\hline ca_(AGR) - & 0 & 0 & 0 & 0 & 0 & 0 & 0 & 0 & \multirow[b]{8}{*}{25} \\
\hline$c a_{-}(\mathrm{ART})-$ & 0 & 0 & 0 & 0 & 0 & 0 & 0 & 0 & \\
\hline ca_(FOR) - & 0 & 0 & 0 & 0 & 0 & 0 & 0 & 0 & \\
\hline$c a \_(W A B)-$ & 0 & 0 & 0 & 1 & 0 & 0 & 0 & 0 & \\
\hline$n p c_{-}(A G R)$ & 0 & 0 & 0 & 0 & 0 & 0 & 0 & 0 & \\
\hline$n p c_{-}(A R T)-$ & 0 & 0 & 0 & 0 & 0 & 0 & 0 & 0 & \\
\hline$n p c_{-}(F O R)-$ & 0 & 0 & 0 & 0 & 0 & 0 & 0 & 0 & \\
\hline$n p c_{-}(W A B)$ & 0 & 0 & 0 & 1 & 0 & 0 & 0 & 0 & \\
\hline$p z_{-}(A G R)-$ & 0 & 0 & 0 & 0 & 0 & 0 & 0 & 0 & \\
\hline$p z_{-}(A R T)-$ & 0 & 0 & 0 & 0 & 0 & 0 & 0 & 0 & \\
\hline pz_(FOR) - & 19 & 23 & 21 & 23 & 21 & 20 & 19 & 17 & \\
\hline $\mathrm{pz} \_(\mathrm{WAB})$ & 1 & 0 & 0 & 8 & 0 & 0 & 1 & 1 & \\
\hline tc_edge_(ALL) - & 0 & 0 & 0 & 0 & 0 & 0 & 0 & 0 & \\
\hline tc_edge_(AGR) - & 0 & 0 & 0 & 0 & 0 & 0 & 0 & 0 & \\
\hline tc_edge_(ART) - & 0 & 0 & 0 & 0 & 0 & 0 & 0 & 0 & \\
\hline tc_edge_(FOR) - & 0 & 0 & 0 & 0 & 0 & 0 & 0 & 0 & \\
\hline tc_edge_(WAB) - & 0 & 0 & 0 & 1 & 0 & 0 & 0 & 0 & -20 \\
\hline ed_(ALL) - & 0 & 0 & 0 & 0 & 0 & 0 & 0 & 0 & \\
\hline ed_(AGR) - & 0 & 0 & 0 & 0 & 0 & 0 & 0 & 0 & \\
\hline ed_(ART) & 0 & 0 & 0 & 0 & 0 & 0 & 0 & 0 & \\
\hline ed_(FOR) - & 17 & 22 & 16 & 25 & 20 & 17 & 16 & 13 & \\
\hline ed_(WAB) - & 0 & 0 & 0 & 0 & 0 & 0 & 0 & 0 & \\
\hline shdi_(ALL) - & 0 & 0 & 0 & 0 & 0 & 0 & 0 & 0 & \\
\hline el_(ART)_with_(AGR) - & 0 & 0 & 0 & 0 & 0 & 0 & 0 & 0 & \\
\hline el_(FOR)_with_(AGR) - & 0 & 0 & 0 & 0 & 0 & 0 & 0 & 0 & \\
\hline el_(WAB)_with_(AGR) - & 0 & 0 & 0 & 1 & 0 & 0 & 0 & 0 & 15 등 \\
\hline el_(FOR)_with_(ART) - & 0 & 0 & 0 & 0 & 0 & 0 & 0 & 0 & 10 음 \\
\hline el_(WAB)_with_(ART) - & 0 & 0 & 0 & 1 & 0 & 0 & 0 & 0 & TO \\
\hline el_(WAB)_with_(FOR) - & 0 & 0 & 0 & 1 & 0 & 0 & 0 & 0 & $\underline{\underline{L}}$ \\
\hline cce_(ART)_with_(AGR)- & 0 & 0 & 0 & 0 & 0 & 0 & 0 & 0 & $\grave{O}$ \\
\hline cce_(FOR)_with_(AGR) - & 15 & 21 & 19 & 22 & 19 & 19 & 16 & 18 & $\tilde{u}$ \\
\hline cce_(WAB)_with_(AGR)- & 0 & 0 & 0 & 1 & 0 & 0 & 0 & 0 & $\frac{4}{0}$ \\
\hline cce_(AGR)_with_(ART) - & 10 & 14 & 14 & 11 & 9 & 13 & 6 & 3 & $\frac{1}{0}$ \\
\hline cce_(FOR)_with_(ART) - & 2 & 2 & 3 & 4 & 0 & 2 & 2 & 4 & ف \\
\hline cce_(WAB)_with_(ART) - & 0 & 0 & 0 & 0 & 0 & 0 & 0 & 0 & $\varepsilon$ \\
\hline cce_(AGR)_with_(FOR) - & 0 & 0 & 0 & 0 & 0 & 0 & 0 & 0 & 10 三 \\
\hline cce_(ART)_with_(FOR) - & 0 & 0 & 0 & 0 & 0 & 0 & 0 & 0 & Z \\
\hline cce_(WAB)_with_(FOR)- & 0 & 0 & 0 & 3 & 0 & 0 & 0 & 0 & \\
\hline cce_(AGR)_with_(WAB)- & 0 & 0 & 0 & 1 & 0 & 0 & 0 & 0 & \\
\hline cce_(ART)_with_(WAB) - & 0 & 0 & 0 & 0 & 0 & 0 & 0 & 0 & \\
\hline cce_(FOR)_with_(WAB)- & 1 & 0 & 0 & 9 & 1 & 0 & 1 & 1 & \\
\hline Ci_np_(AGR) - & 0 & 0 & 0 & 0 & 0 & 0 & 0 & 0 & \\
\hline ci_np_(ART) - & 0 & 0 & 0 & 0 & 0 & 0 & 0 & 0 & \\
\hline Ci_np_(FOR)- & 0 & 0 & 0 & 0 & 0 & 0 & 0 & 0 & \\
\hline ci_np_(WAB) - & 0 & 0 & 0 & 0 & 0 & 0 & 0 & 0 & -5 \\
\hline ci_pa_(AGR) - & 0 & 0 & 0 & 0 & 0 & 0 & 0 & 0 & \\
\hline ci_pa_(ART) - & 0 & 0 & 0 & 0 & 0 & 0 & 0 & 0 & \\
\hline ci_pa_(FOR) - & 0 & 0 & 0 & 0 & 0 & 0 & 0 & 0 & \\
\hline ci_pa_(WAB)- & 0 & 0 & 0 & 0 & 0 & 0 & 0 & 0 & \\
\hline ci_pp_(AGR) - & 0 & 0 & 0 & 0 & 0 & 0 & 0 & 0 & \\
\hline ci_pp_(ART) - & 0 & 0 & 0 & 0 & 0 & 0 & 0 & 0 & \\
\hline Ci_pp_(FOR) - & 1 & 0 & 0 & 0 & 0 & 0 & 0 & 0 & \\
\hline ci_pp_(WAB) - & 0 & 0 & 0 & 0 & 0 & 0 & 0 & 0 & \\
\hline ci_ca_(AGR) - & 0 & 0 & 0 & 0 & 0 & 0 & 0 & 0 & 0 \\
\hline ci_ca_(ART) - & 0 & 0 & 0 & 0 & 0 & 0 & 0 & 0 & \\
\hline Ci_ca_(FOR)- & 0 & 0 & 0 & 0 & 0 & 0 & 0 & 0 & \\
\hline ci_ca_(WAB) - & 0 & 0 & 0 & 0 & 0 & 0 & 0 & 0 & \\
\hline Ci_cp_(AGR) - & 0 & 0 & 0 & 0 & 0 & 0 & 0 & 0 & \\
\hline ci_cp_(ART) - & 0 & 0 & 0 & 0 & 0 & 0 & 0 & 0 & \\
\hline Ci_cp_(FOR) - & 0 & 0 & 0 & 0 & 0 & 0 & 0 & 0 & \\
\hline ci_cp_(WAB) - & 0 & 0 & 0 & 0 & 0 & 0 & 0 & 0 & \\
\hline & 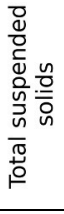 & 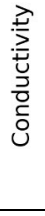 & 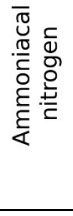 & 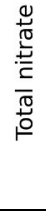 & 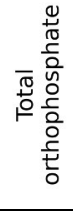 & 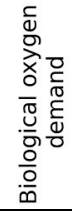 & 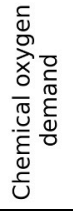 & 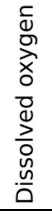 & \\
\hline
\end{tabular}




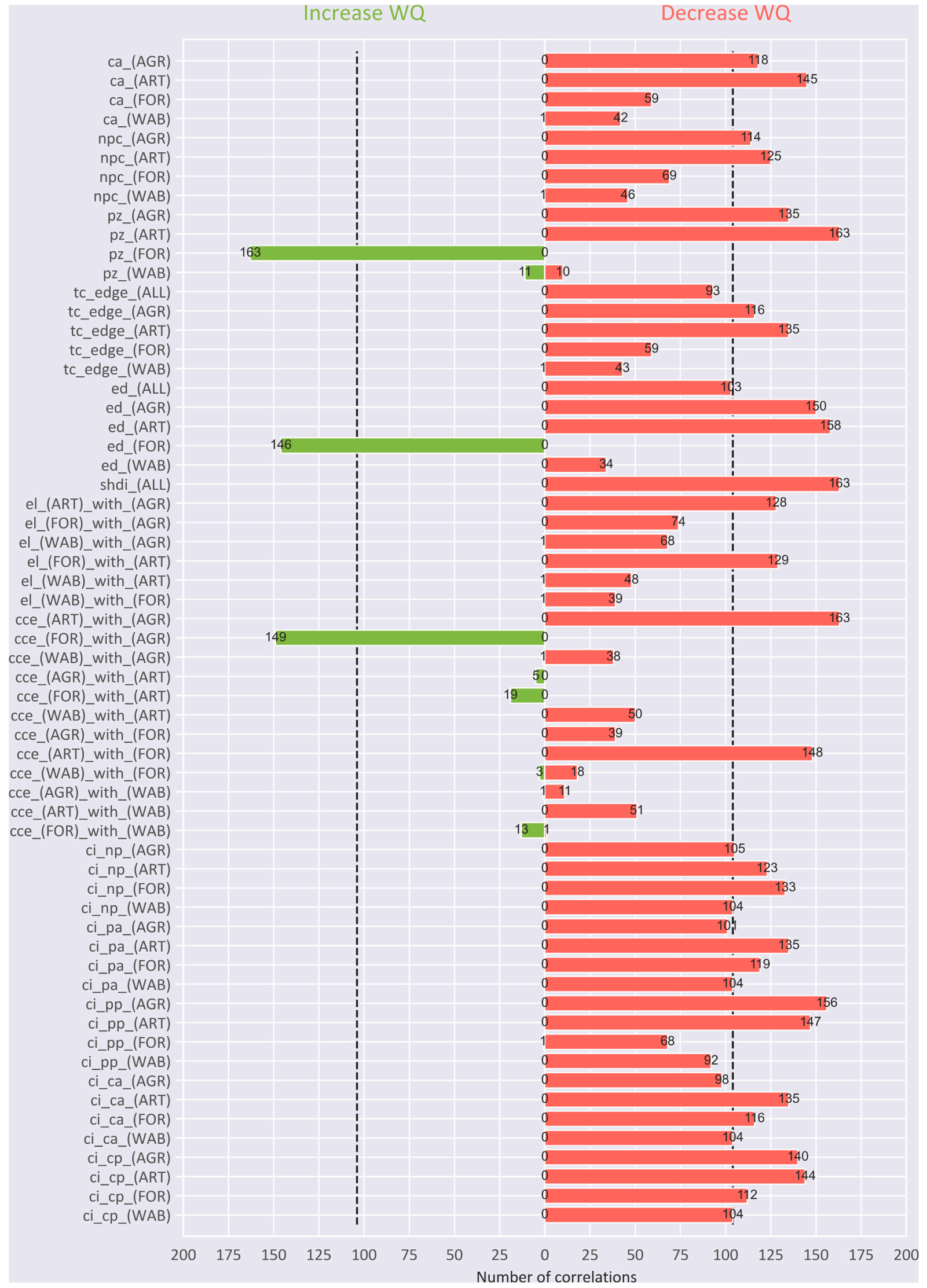

Fig. 5. Number of correlations that indicate decrease/increase of water quality for each LSM. 

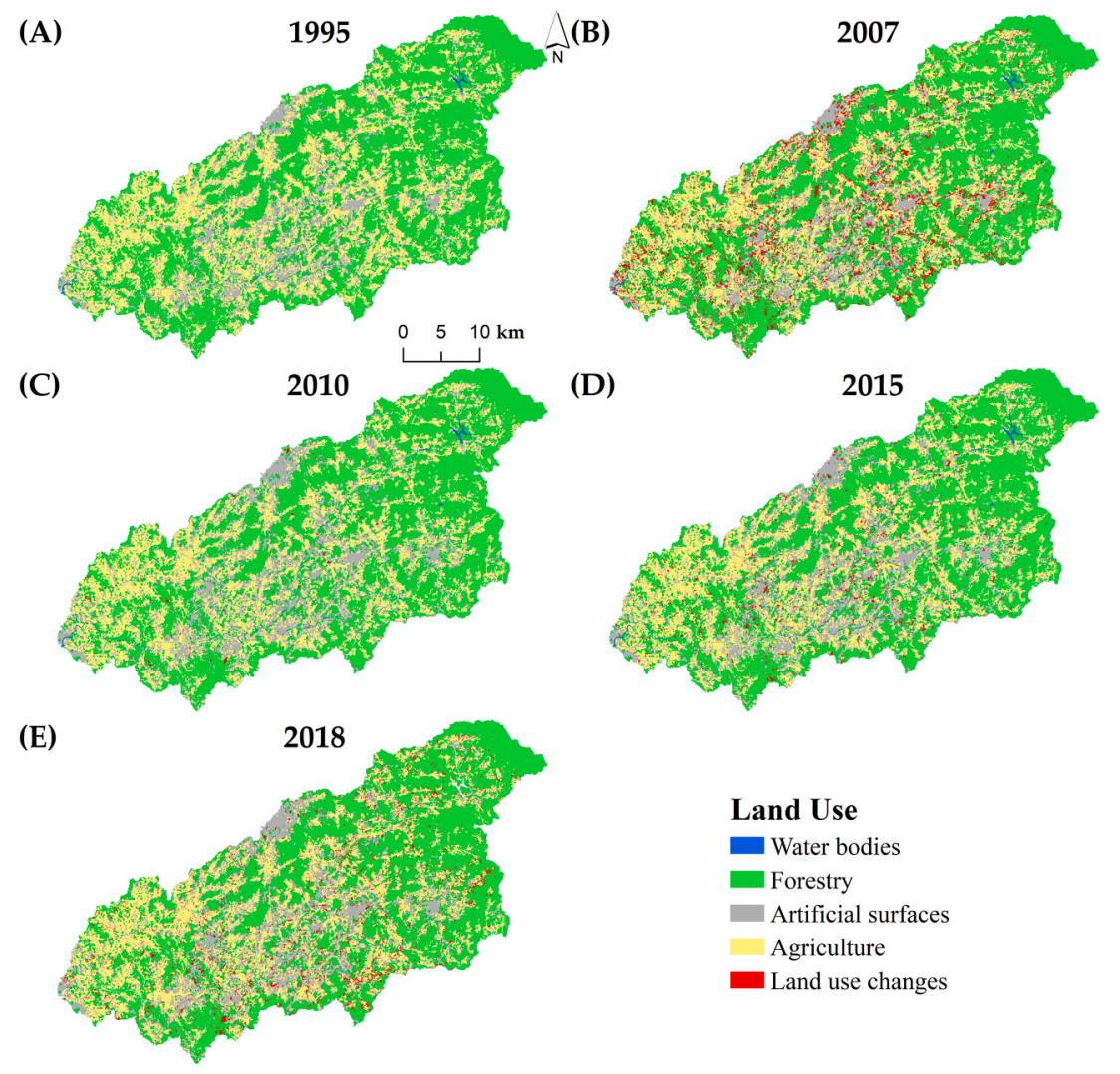

Fig. 6. Ave river basin land uses. The Figures (A) to (E) are the land use maps for 1995, 2007, 2010, 2015 and 2018, respectively.

adverse effect and a tendency to decrease, it was assumed that only monitoring is required since these are under a desirable scenario.

\section{Results}

\subsection{Spearman's correlation rank example}

In Fig. 4(A) and (B) is demonstrated the scatter plot of measurements and respective $r_{s}$ values for the HYs of 2000-2001 and 2010-2011 between biological oxygen demand (BOD) and the percentage of connection area for agricultural areas, denominated as ci_cp_(AGR).

In the HY 2000-2001, the number of sampling sites was 10 . So to reject the null hypothesis, the $r_{s}$ absolute value should be higher or equal to 0.648 . Since the $r_{s}$ value is 0.803 , the correlation is statistically significant, meaning that ci_cp_(AGR) increased BOD in the HY 2000-2001. For the HY 2010-2011, the number of BOD measurements was 22, which requires an $r_{s}$ absolute value higher or equal to 0.425 to reject the null hypothesis. The obtained $r_{s}$ was near to zero, 0.062 , which is much lower than the critical $r_{s}$ value, so for the respective HY, it is assumed that the ci_cp_(BOD) had no statistical influence in the BOD concentration.

The analysis of BOD and ci_cp_(AGR) correlations for all the analysed HYs is portrayed in Fig. 4(C). To identify if $r_{s}$ is statistically significant, it was compared with the critical value (black line), which is dependent on the number of sampling sites, Table A.1. Note that all the correlations (blue circles) are positive, which indicates that ci_cp_(AGR) is a landscape metric that increases the SWP for many HYs. Eighteen of the correlations are higher or equal to the critical value (marked with a black buffer), and 6 were lower (red crosses). In Fig. 4(D) is demonstrated the same analysis but between BOD and the percentage of forested areas, $\mathrm{pz}_{-}(\mathrm{FOR})$. In this case, the correlations are negative, which indicated that pz_(FOR) decreased the biological oxygen demand.

\subsection{Landscape metrics $v$ s surface-water parameters}

In the supplementary material is demonstrated the number of statistical significant correlations that increase/decrease water quality for each SWP during different hydrological years Table S.2 and Table S.3, and Fig. S.2. In Tables 2 and 3 is depicted a similar analysis, but in this case, each column is a SWP, and lines are LSM. Thereby, values inside Tables 2 and 3 are the number of HYs with a statistically significant correlation between the respective SWP and LSM. Table 2 contains the number of correlations that decrease WQ, and Table 3 the number of correlations that increase WQ. In Fig. 5 is demonstrated the total number of correlations that increase/decrease water quality for each LSM. In the supplementary material, this analysis was also made for the HYs and SWP, Fig. S. 2 ad S. 3, respectively.

Among the 61 LSM, a total of 34 has a NOC higher than 104, Fig. 5. According to the selected methodology, that 34 affect WQ in the studied period, of which 31 decreases while the remaining 3 increase it. Metrics associated with the improvement of water quality are the percentage of forested areas, pz_(For), with 163 correlations, the number of forestry edges shared with agricultural fields, divided by the length of agricultural edges, cce_(FOR)_with_(AGR), with 149 correlations, and the edge density of forested areas, ed_(FOR), with 146 correlations.

The LSC negative impacts on WQ are associated mainly to agricultural and artificial surfaces, which can be verified for the metrics: total area (ca), percentage of area (pz), number of patches (npc), total edge (tc_edge), edge density (ed). Still, these metrics have a higher NOC for artificial surfaces rather than to agricultural areas. A total of 4 contrast metrics show a negative effect on WQ. The edge length between artificial surfaces and agricultural areas, el_(ART)_with_(AGR) with 128 correlations, and also the same metric but divided with the total edges of agricultural surfaces, cce_(ART)_with_(AGR), with 163 correlations. The contrast between forested areas and artificial surfaces is curiously a LSC with a negative impact because el_(FOR)_with_(ART) had 129 
correlations and also the cce_(ART)_with_(FOR) with 148. The diversity of land uses decreases WQ since shdi_(ALL) has a NOC of 163, which is the maximum, that was also found for $\mathrm{pz}_{-}(\mathrm{ART})$ and cce_(ART)_with_ (FOR).

Among the LSC that decrease WQ, part of them shows an unforeseen result since it was expected that they would decrease WQ, which is the case of connectance for water bodies and forested areas. In general, these LSC showed a negative impact on water quality, and none of them had a positive effect. Only ci_pa_(AGR), ci_pp_(FOR), ci_pp_(WAB) and ci_ca_(AGR) did not have a NOC higher than 103.

\subsection{Intervention analysis}

In terms of composition, ARB has suffered notable changes, represented in Fig. 6 . In overall, the river basin presented significant changes in the increase of agricultural areas and artificial surfaces and the decrease of forestry. For agricultural areas, there was a drop of land occupied from 1997 to 2010 , since the occupied area was $32.9 \%$ and then $29.7 \%$ (in 2007 and 2010), but in 2015 there was an increase into $30.8 \%$, and in the most recent map the river basin is occupied by $35.4 \%$, which is the highest percentage of agricultural land use. Initially, artificial surfaces occupied the river basin by a total of $15.6 \%$. In 2007 there was a high increase to $19.3 \%$, and in the following years, there was a minimal increase to $19.5 \%$ in $2010,19.9 \%$ in 2015 , but according to the land use map of 2018 , there was a decrease of $2 \%$ into $18.1 \%$. Water bodies did not suffer any changes until 2018 since the occupation percentage was around $0.35 \%$, but in 2018 there is noted a slight decrease to $0.27 \%$. Forest is the land use type that has a continuous decrease over the years. In 1997 the land was occupied by $60.5 \%$ of forested areas, but in the following years, it decreased to $50.6 \%, 50.4 \%, 48.9 \%$ and then to $46.2 \%$ for each land use map respectively.

More than half of the LSC influenced the river basin WQ (34). It is understood that intervention must be done in order to preserve/improve freshwater resources. Since it is an impossible task to rearrange an entire river basin landscape, it was made an intervention analysis to prioritise which LSC require intervention, based on the land use tendencies, as presented in Table B.1. According to the adopted methodology, it is proposed different types of intervention priorities, classified as interventions in the short or long term and LSC that should be under monitoring. The intervention in the short term is proposed for the most urgent cases, for LSC that influence WQ (more than 103 correlations), and the metric change tendency is in the worst-case scenario, increasing tendency and decrease of WQ or decreasing tendency and an increase of WQ. The long-term interventions were proposed for LSC with NOC $\geq 104$ and a low variation rate. The proposed LSC for monitoring are the ones that have also have an impact on WQ, but the LSC variation is favourable for WQ (increasing tendency and increase of WQ or decreasing tendency and a decrease of WQ).

The intervention analysis is reported in appendix, Table B.1. In resume, a total of 25 LSC should be under monitoring, 6 should be intervented for the long term and 3 for the short term, while for the remaining 27 it was not ascribed any intervention priority. The proposed short-term interventions should be applied in the LSC measured by the respective LSM: ca_(AGR), pz_(AGR) and ed_(FOR). Both of the LSC related to agricultural land uses are quite similar since ca_(AGR) is the total area and pz_(AGR) is the percentage. This means that agricultural areas decrease ARB WQ not only in proportion but also in quantity. On the other hand, the edge density of forested areas increases WQ with a total of 146 correlations. For this LSC, it was assigned a short-term intervention because the tendency is to decrease, with a variation of $-32.6 \%$.

LSC that require a less urgent intervention (long-term) are predominantly related to artificial surfaces and forestry. These LSC show a low variation but a strong effect on WQ, ca_(ART), pz_(ART), shdi_(ALL) and cce_(ART)_with_(FOR) decrease WQ with a NOC of 145,163, 163 and 148 respectively. The long-term interventions on LSC that increase WQ should be the increase of forested areas and contrast between forests and agricultural fields, since the NOC of pz_(FOR) and cce_(FOR)_with_ (AGR) is 163 and 149, respectively. The results reflect that artificial surfaces decrease WQ both in proportion and quantity. The Shanon's diversity index is an indicator of anthropogenic activity since it represents the diversity of land uses. Besides this LSC has a very low variation $(0.1 \%)$, it has a substantial impact on WQ, and it is why it should be intervened. The percentage of forested edges length that is paired with artificial surfaces, is another LSC that demands a long-term intervention since the LSM cce_(ART)_with_(FOR) has 148 correlations and a variation rate of $-6.1 \%$. On the other hand, the percentage of agricultural land use patches length that are alongside forestry land uses increases WQ, with 149 correlations and a variable rate of 3.6\%. Forested areas are decreasing in AVR, but the variation rate is only $-6.5 \%$. Still, the percentage of forestry must be increased in the long term since it has a clear effect on improving WQ.

For many LSC, it was attributed the intervention class of monitoring, a total of 25. None LSC that were classified with this priority had a positive impact on WQ. The offset for these cases is that the metric tendency is to decrease, having a variation rate lower than $-10 \%$. Almost all the LSC related to connectance revealed a negative impact on WQ and a decreasing tendency independently of the land use type. Among them, only ci_pp_(FOR), ci_pp_(WAB) and ci_ca_(AGR) did not have effect on WQ. Still, other twelve LSC require monitoring in ARB. Among them are the number of patches of agricultural areas and artificial surfaces, npc_(AGR) and npc_(ART) respectively, the total edge of the same land-use types, tc_edge_(ART) and tc_edge_(AGR) and also the edge density ed_(ART) and ed_(AGR). Not only the total length (el) but also the percentage (cce) of agricultural areas that are shared with artificial surfaces are other LSC that require monitoring, el_(ART)_with_ (AGR) with 128 correlations and cce_(ART)_with_(AGR) with a higher impact since it presented 163 correlations. Lastly, the total edge of forested areas that are shared with artificial surfaces, el_(FOR)_with_ (ART), is another LSC that requires monitoring.

\section{Discussion}

\subsection{Water quality vs landscape}

Commonly, when temporal variations are approached, authors mainly use only seasonal changes due to their influence in contamination phenomena (Fernandes et al., 2019b; Shi et al., 2017; Ye et al., 2014). In the present study, the temporal changes were studied across different HYs, despite the seasonal effects, to catch successive effects by analysing consecutive HYs. It was analysed a total of 26 HYs in order to understand if the correlations were consistent and not random. The presented results in Table S.2 and Table S.3, clearly shown that there are high variations of correlations depending on the analysed SWP and also across different HY. This can happen for two possible reasons. The first is that the precipitation of each HY is different, which can make diffuse pressure effects change over the years. The second reason is that, as portrayed in Table A.1, the number of sampling sites and also the location of sampling sites with data is different for each HY. Besides, they are all located in ARB, different sampling sites represent different locations and consequently have a distinct Strahler order, which can affect the results, as other authors studied (Ding et al., 2016). The given reasons might explain the SWP variations along the HYs, in correlations (Tables S.2. and S.3) and averages (Fig. S.1). Still, it cannot be forgotten that another factor that influences the results is the released contaminants from point source pressures (Fernandes et al., 2019), which change over the years. As other authors have mentioned (Alves et al., 2009; Gonçalves et al., 1992; Soares et al., 1999), in ARB the period with the highest impact of point source pressures could be during the second half of the 20th century, which can possibly justify that in the first analysed HYs conductivity, ammoniacal nitrogen, total orthophosphate, and biological oxygen demand had the highest values. Also, the low 


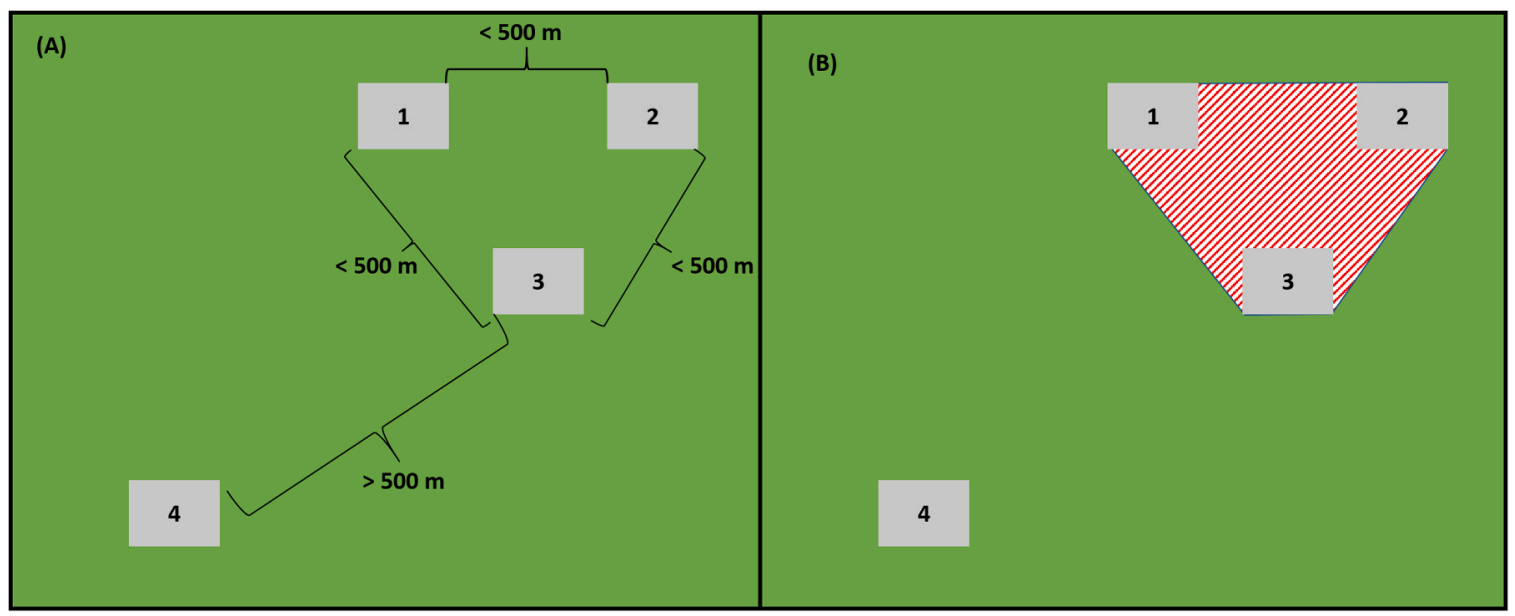

Fig. 7. Given example for the calculation of connectance metrics. (A) representation of 4 land use patches and connectance range. (B) Connectance area.

(A)

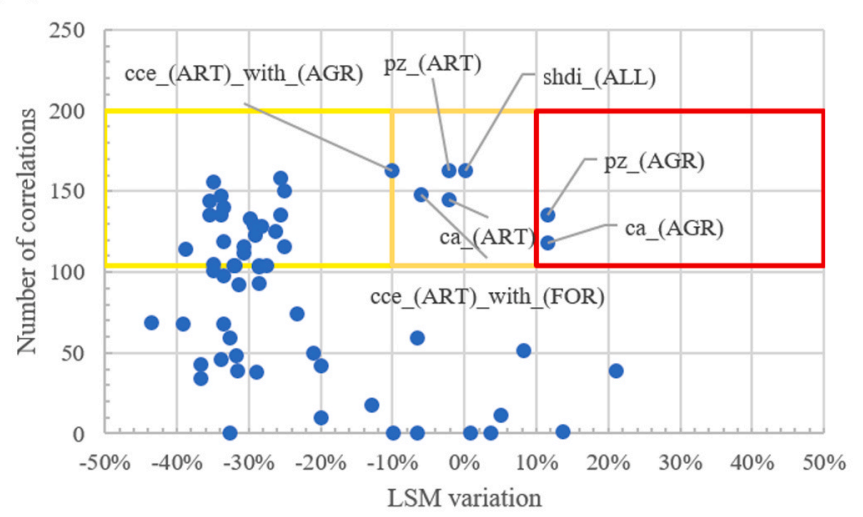

(B)

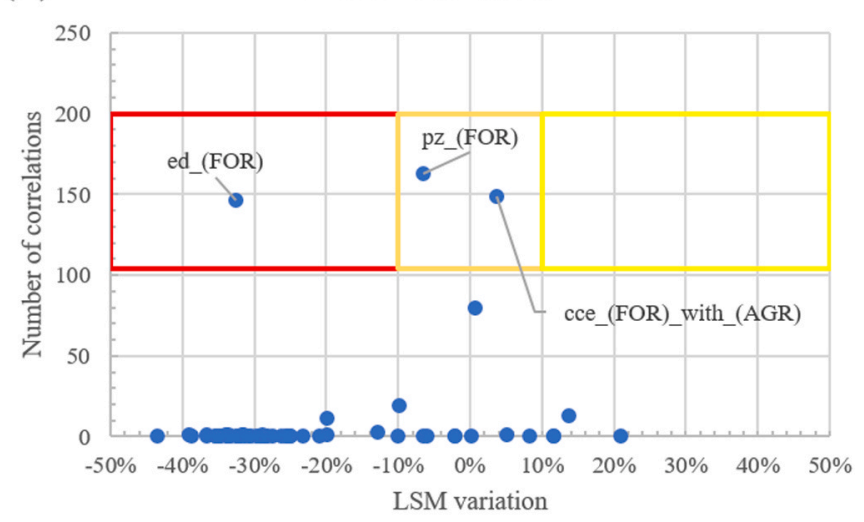

- Short-term $\longrightarrow$ Monitoring Long-term

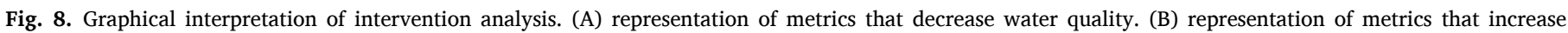
water quality.

number of statistically significant correlations between the period of 1988-1992 can be due to the fact that when point-source pressures have a substantial effect on WQ, consequently the effect of LSC can be masked (Ahearn et al., 2005; Sliva and Williams, 2001; Yu et al., 2016). Due to the mentioned interactions and dispersion of sampling sites, it was chosen the threshold of 104 correlations, to tag if a LSC has effect on ARB water quality. For this analysis, it was chosen the Spearman's correlation rank because the correlation is not affected by the difference of values or the type of function (Zar, 2005), while if it was chosen to use Pearson correlation, it would be expected that many correlations would be non statistically significant since the relations might not be linear, as shown in Fig. 4(A). The comparison between contaminant concentrations and respective legal recommendations revealed that some contaminants are more preoccupying than others. From this point of view, other authors used multicriteria analysis to give different weights to different factors (Terêncio et al., 2017). In the intervention analysis, it was not given importance to different contaminants because even when the concentrations are inside legal limits, there can be traced damages in the ecological integrity (Fonseca et al., 2017, 2016). Also, this analysis was based on the SWP that had available data for an extended period, which does not mean that in other applications in other river basins, other parameters can be encompassed.

As other authors have explained, artificial surfaces are feasible to create diffuse pollution (Shi et al., 2017). Besides, urban areas can also be linked to point source pressures, urban areas are impervious and contain multiple forms of contamination (Wei et al., 2020), which are released with rainfalls (Zhang et al., 2020), and the drainage can be routed surface waters (Ahearn et al., 2005). This study revealed that in $\mathrm{ARB}, \mathrm{LSC}$ related to agriculture and urban land uses predominantly decrease water quality. However, when comparing both, artificial surfaces have a stronger effect on water quality. When comparing the same types of metrics for both, the number of significant correlations was higher for urban land uses, in all the metrics ca, npc, pz, tc_edge, ed and all the ones associated to connectance. At this point is clear that in ARB, artificial areas have a stronger effect than agriculture, possibly because in impervious surfaces, the runoff flow is higher rather than in agricultural fields (Zhang et al., 2020; Wei et al., 2020). Nevertheless, in terms of intervention, agriculture is more preoccupying in ARB since the percentage of agricultural areas are increasing with a variation rate of $11.6 \%$, while artificial areas have a lower change rate Table B.1. When analysing the combination of both land uses through contrast metrics, is seen that the total edge that is shared between both, el_(ART)_with_ (AGR) has a substantial NOC, 128, but the highest number correlation is achieved for the percentage of agricultural edges that are shared with urban areas, with 163 correlations, cce_(ART)_with_(AGR). Surprisingly the percentage of urban edges that are paired with agricultural areas, cce_(AGR)_with_(ART) has a total of 80 correlations that increase water quality, which is hard to explain.

According to Forman (1999), land uses created by humans hold harder edges, which induces a higher edge density. In contrast, tc_edge_ 


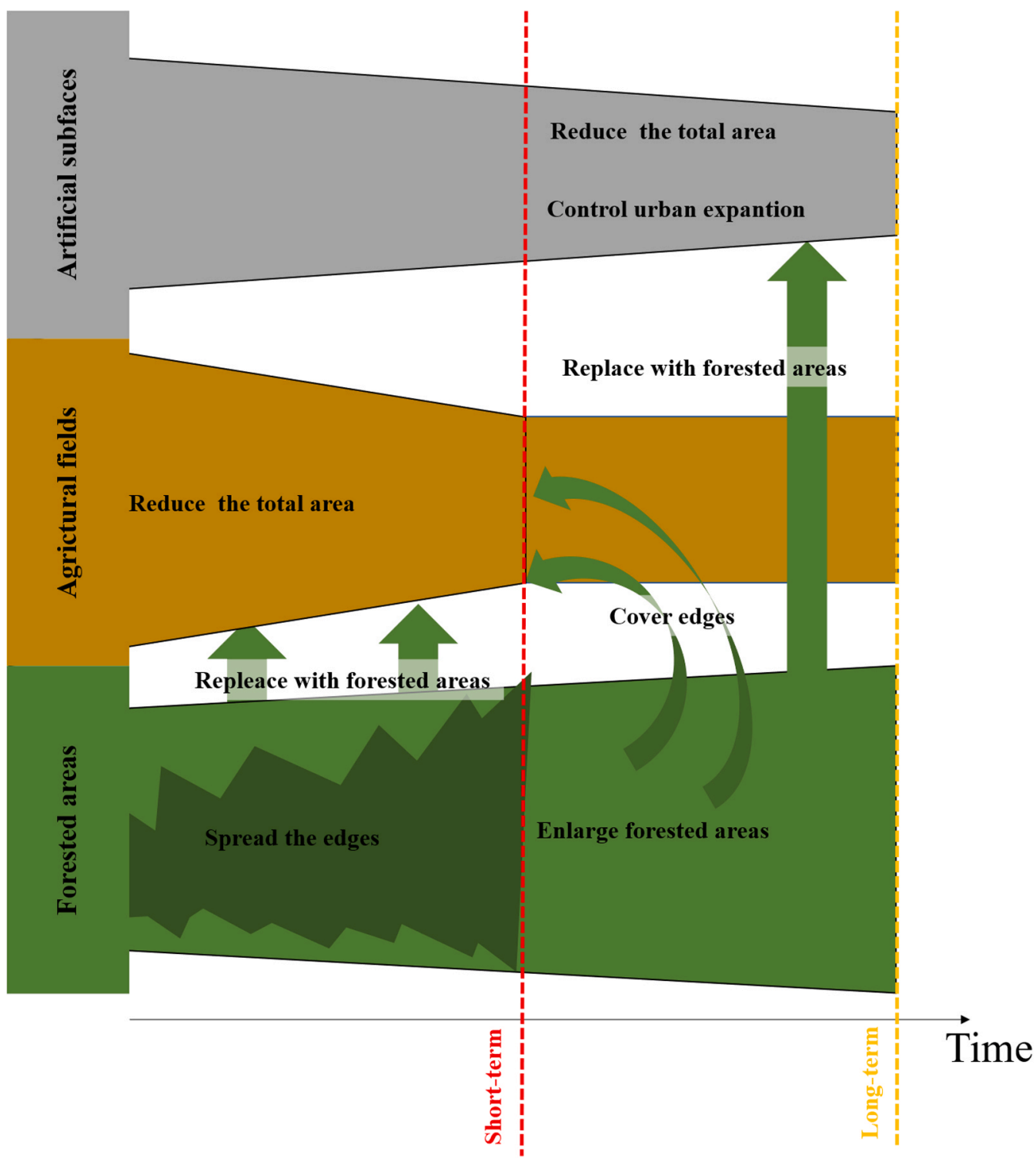

Fig. 9. Proposed landscape intervention.

(ALL) and ed_(ALL) and did not achieve a high number of statistically significant correlations (93 and 103, respectively), so the variety of edges among all land uses did not have a pronounced effect in Ave river basin. However, another metric that reflects anthropogenic activity is Shannon's diversity index. In the present study, shdi_(ALL) has a NOC of 163 , indicating that in catchments with a high diversity of land uses is found poor WQ. In concordance to many authors, SHDI is positively correlated to many contaminant concentrations (Lee et al., 2009), indicating negative impacts of farmland and urban land on water quality (Zhang et al., 2019). However, in another study, applied to south Estonia, it was found that this index is positively correlated to the concentration of BOD, COD and total nitrate, but without statistical significance (Uuemaa et al., 2005).

Independently of the land use type, for most of the connectance LSM, the respective LSC revealed a negative impact on water quality. It is quite hard to figure out why these LSC are associated with the degradation of WQ, but possibly connectance is also a measure of the diversity of land uses. It is reminded that the connectance threshold for this study was $500 \mathrm{~m}$, which means that as more dispersed land use patches exist within the defined range, the value of these metrics will become higher. This can be explained according to the given example in Fig. 7.
In Fig. 7(A) are represented 4 land use patches, numbered from 1 to 4. As it can be seen, 1, 2 and 3 are connected within a range of $500 \mathrm{~m}$, while the patch 4 is not. When the connectance metrics are calculated, it is created a connection polygon (Adamczyk and Tiede, 2017), represented with the red stripes in Fig. 7(B). For the connectance metrics referred in Table 1, the ci_np, the number of connected patches is 3 . The patch area within the range of connection, ci_pa, is the total area of the 3 connected land use patches, while the percentage, ci_pp, is the same area divided by the total analysed area, which is the green square. The connection polygon is used in the calculation of ci_ca and ci_cp, the first is the polygon area, while the second is the same area divided by the total analysis area, the green square. As more patches exist in the range of connection, as more patches exist, all these metric values increase. So, as more natural is a region, less different land use patches exist, where the is a predominance of forested and semi-natural regions. For that kind of regions there is low connectance since it is occupied with large patches of natural land uses. Since ARB is an urbanised river basin, there is a high diversity of patches, connected in a range of $500 \mathrm{~m}$, possibly for the connection threshold connectance metrics operates as a measurement of anthropogenic activity as like Shannon's diversity index. In concordance to Amaral et al. (2019), fragmented landscapes increase 
with anthropogenic activity, which makes that connectance metrics as indicators of anthropogenic activity, which are related to the decrease of water quality (Shehab et al., 2021). In concordance to other studies, forested as natural areas improve surface water quality (Li et al., 2009; Shi et al., 2017; Wan et al., 2014) since in pz_(FOR) revealed 163 correlations and ed_(FOR), 146. However, other LSC associated with forestry had no impact, which are total area and total edge. This means that in ARB, the effect of forestry areas is based on proportion as in other studies (Rodrigues et al., 2018; Uuemaa et al., 2005; Yong and Chen, 2002). However, in terms of edge density and number of patches, other authors found positive correlations with contaminant concentrations (Lee et al., 2009). In the present study, the number of patches of forested areas was positively correlated to some SWP, with a total of 69 correlations, which for the respective LSC is assumed as non-effective since the NOC is lower than 104. Generically the results aim that in ARB, forested areas should not be spread, but yet together and longed. The percentage of agricultural patch edges shared with forestry areas, cce (FOR)_with_(AGR), has a positive effect on water quality. This means that the presence of forested areas mixed with agricultural fields can not degrade water quality but even have a positive interaction effect. This was also identified in another study that resorted to the combined effect of both land uses (Pissarra et al., 2019). On the other hand, the combination of forested areas with artificial surfaces degrades WQ since el_ (FOR)_with_(ART) and cce_(ART)_with_(FOR), had a NOC of 129 and 148 , respectively. These two metrics point out that in areas with high edges of artificial surfaces, the effect of forest cannot suppress the damages from artificial areas, which can happen with high human activity (Decatanzaro et al., 2009; Morrice et al., 2008). But another possible cause is that in artificial areas can be placed effluent discharges that degrade water quality (Wilson and Weng, 2010), and as Shehab et al. (2021) suggested, point source emissions can have a stronger influence on water quality rather than non-point pressures.

The effects of the riparian vegetation were also boarded in this study by calculating the linked edges of forested areas with water bodies in three metrics, el_(WAB)_with_(FOR), cce_(WAB)_with_(FOR) and cce_ (FOR)_with_(WAB). As a result, these metrics were poorly correlated to the SWP. These results were not expected since it is supposed that riparian vegetation improves WQ (Hill, 1996). Besides the metrics represent riparian zones, the adopted scale was the entire upstream catchment was other authors suggested (Araújo Costa et al., 2019; Ding et al., 2016; Li et al., 2012; Zhang et al., 2019). As Ramião et al. (2020) have studied in ARB, riparian vegetation has a beneficial effect on water quality, but in that study, the sampling sites were located in the upstream region of the river basin, and in the present study the sampling sites are scattered across the entire river basin. Possibly, the lack of correlations for the contrast between water bodies and forested areas might be due to the chosen scale since authors achieved statistical response when addressed to a riparian scale (Dodds and Oakes, 2008; Johnson et al., 1997; Tran et al., 2010), or even, the existing riparian corridors might not be effective, due to the presence of non-suitable vegetation or due to the lack of riparian extension.

\subsection{Intervention}

The final task of the present study is to provide an intervention analysis by referring to which LSC require intervention and prioritise those interventions. For that, it was combined the correlation counts with the LSM variations. As a result, the intervention should be applied in 3 LSC urgently, in the short-term, 6 in the long-term, and 25 should be under monitoring, Table B.1 and Fig. 8. The total area and percentage of agricultural surfaces, ca_(AGR) and pz_(AGR), increase the contamination of several SWP along many HY, and also at the same time, these metrics have a tendency to increase that should be countered, in order to do not increase the proportion of agricultural fields and foremost to reduce their expansion.

The presence of elonged forestry patches increases WQ, since unfragmented forests improve water quality (Shehab et al., 2021). This is also confirmed in the present study, since the npc_(FOR), number of patches of forestry areas has a NOC that decrease water quality is 69, Fig. 5. For such reasons, urgent increase elongated forested areas that are decreasing in the last years, especially near agricultural areas, to use forests as net sinks of contaminants (Santos et al., 2015a) that result from agricultural areas, towards runoff flow.

Not so urgent is necessary to intervene in other 6 LSC. Both ca_(ART) and $\mathrm{pz}_{-}$(ART) should be decreased for the long term. At the same time, this study results indicated that SHDI and cce_(ART)_with_(FOR) should also decrease because both of these LSC have a negative impact on WQ. Both are related to artificial land uses, and by decreasing the areas of artificial surfaces, consequently shdi and cce_(ART)_with_(FOR) will also decrease. It still is important to note that the LSC cce_(ART)_with_(FOR) has a negative effect on WQ, but it cannot be presumed that the combination of forest land uses degrades more WQ than artificial surfaces itself, possibly in ARB the effect of artificial surfaces is higher than the effect of forested areas. The percentage of forested areas, pz (FOR) must be increased for the long term. By increasing the percentage of forested areas and edge density, the cce_(FOR)_with_(AGR) will also increase, which was one of the LSC that was tagged as a long-term intervention. Ideally, a proportion of artificial surfaces should be replaced by forested areas. This type of intervention is high cost since artificial areas hard to change (Salgado Terêncio et al., 2019). In practical terms, is something that can only be done in long periods and is a delicate process since artificial surfaces also contain residential areas. The reduction of artificial areas is a complex procedure, which can become considered by decision-makers as an unenforceable solution. In that case, the reduction of urban land use impacts on WQ must be regarded, with measures such as optimisation of riparian zones and enhancement of urban runoff drainage routes, and, as Gu et al. (2019) suggested, the construction of urban areas near riparian zones should be prohibited, which are a convenient basis for urban sprawl (Li et al., 2020).

As listed in Table B.1, 25 LSC should be under monitoring. Those decrease WQ, but the upside is that these have a decreasing tendency that is favourable to WQ. Besides, it was given a priority of "monitoring", it does not mean that it should not be made an intervention on those LSC in future. For monitoring LSC, it is alerted that it should be given to attention during future years and should be continuously evaluated, not only the increasing/decreasing tendency but also the impact on WQ with recent data. In Fig. 8 is seen that cce_(ART)_wth_(AGR) has a variation rate that is slightly lower than $-10 \%,-10.01 \%$. This LSC was considered as monitoring, but it is almost in a breakpoint to be tagged as a long-term intervention, Fig. 8. Still, it should be given specific attention to the connectance metrics. Nevertheless, for these metrics, it should be applied future studies by using other connectance ranges to detect which is the range shows a stronger statistical connection, or even if there is a range where the connectance has a positive effect.

Briefly, the changes that have to be done are reducing agricultural areas in the short term, reducing artificial surfaces in the long term if possible, Fig. 9. At the same time, the forest areas should be spread in elongated shapes, and the reduced agricultural areas and also artificial surfaces should be replaced by forestry. Still, the reduction of artificial areas might be hard because it is a high-cost effort, but it is mandatory to reduce the urban expansion (Habibi and Asadi, 2011). The reduction of agricultural areas should be made in locations near to surface water, and by replacing them with forested fields, this would reduce the contaminant flow and protect the surface waters (Allan et al., 1997), ever since the water and sediment connectivity is higher in agricultural fields rather than in forests (Masselink et al., 2017; Shehab et al., 2021).

Still, as other authors recommended, the created forested areas should not be fragmented in various land use patches but as forestry corridors (Lee et al., 2009), which can retain more contaminants (Amiri and Nakane, 2008; Uuemaa et al., 2005). Besides the connectance of water bodies with forestry areas did not reveal a high NOC, the forestry extensions should be also be enforced as riparian corridors, which also 
brings a chance to enhance fluvial ecosystems (Costa et al., 2012). This is an environmental strategy that is essential to reduce the environmental costs from the urban and agricultural land use that is effective, according to the results from Ramião et al. (2020). The increase of forested areas aims to accomplish the water framework directive objectives of reaching good or higher ecological status until 2027 (Carvalho et al., 2019). At the same time, the implementation of forested areas decreases the emission of greenhouse gas emissions, mitigating climate change, which also affects the relationship between land use and water quality (Messina et al., 2020; Mishra et al., 2020), and is a necessary strategy to apply, ever since in 2018 the European Union adopted the land use and land use change forestry regulation LULUCF (Duffy et al., 2020). However, the application of grassland instead of forest might have a better cost-effect ratio (Wang et al., 2020), that according to Zhang et al. (2020) is a land-use negatively correlated with contaminant concentrations.

With the proposed interventions, Fig. 9, ca_(AGR), pz_(AGR), ca (ART), pz_(ART), shdi_(ALL), cce_(ART)_with_(FOR) decrease, and $\mathrm{pz}_{-}$ (FOR) and ed_(FOR) and cce_(FOR)_with_(AGR) increase. The implementation of these measures depends on the effort that ARB between all the affected municipalities, not only to improve the land use management but also in the implementation of functional policies such as payment for ecosystem services (Long et al., 2020), and the promotion of best management practices (Chang et al., 2021) are a step forward in the improvement of water resources.

Agriculture by itself cannot be seen as a problem. The cause that leads to assume that agriculture is a harmful land use is because they work as an input for pesticides, fertilisers and organic manure that end up in surface waters (Zhang et al., 2014). Another aspect that has to be implemented in the short term is the enforcement of sustainable agriculture (Altieri and Nicholls, 2012; Garrett, 2013), which would decrease its impact on water quality, and with such practices the required decrease of agricultural areas does not need to be abrupt. In China, the policy of "Returning Cropland to Forests" is being adopted to restore ecological land (Wei et al., 2020), which is similar to the LULUCF (Duffy et al., 2020). By replacing agricultural fields with forests, the improvement of water resources can be notable for the long term. According to the results of Duffy et al. (2020), a reduction of $10 \%$ of agricultural areas increases water quality significantly. However, the impacts of the initial afforestation must be controlled since, in the short term, degrade water quality due to the site preparation and fertiliser application (Binkley et al., 2004; Clarke et al., 2015), and also possible crop rotation must be carefully planned, minimising the impacts on water quality (Hughes and Quinn, 2019).

Besides, this study exposes the necessity to interview the landscape of ARB, point source pressures shout not be minimised since they are a real threat that has been denounced in previous studies (Fernandes et al., $2019,2018)$. In fact, there are national plans that englobe many water resources management, that also includes measures to improve and protect water quality, called as (PGRH) Portuguese Management Plan of Hydrographic Regions. Those measures pay special attention to point source pressures and also to diffuse pressures. Still, the strategies to reduce diffuse pressures englobe monitoring of surface waters but do not encompass land use configuration. Besides ARB is a catchment with intense anthropogenic activity, the present study has shown, and also previous ones (Fernandes et al., 2019a), that landscape is tied to water quality, and for such reasons, the landscape concerns of ARB should be addressed in PGRH. So the present study brings a challenge to all the municipalities that are located in ARB to consider the proposed landscape changes with the intent to conserve and improve the water quality. Besides, the results of the present study are in concordance to others, it should not be extrapolated to other river basins since these relations are a regional issue (Dow et al., 2006; Gove et al., 2001; King et al., 2005).

In the present study, the effects of LSC were accessed for almost three decades in order to understand if the relations with surface water parameters were consistent by analysing consecutive hydrological years.
Since the present study was supported by correlation analysis, the effects of each metric are exposed by a pair relationship, and the combined effects were not accessed, as in other studies that resorted to multivariate methods (Acuña-Alonso et al., 2021; Fernandes et al., 2019a). More research must be done in ARB in the scope of land use vs water quality. Since the present results are shown as a generic relation for the entire river basin, it is necessary to which areas have more effect in terms of LSC on water quality, which can be detected by applying multicriteria analysis for prioritisation purposes (Camara et al., 2020), or even the application of more complex methodologies such as self-organising map (Gu et al., 2019). Catchment prioritisation is a strategy to support decision-makers to identify the most critical regions that demand intervention. Also, it is necessary to predict the impacts of possible land use changes, which can be done through software such as SWAT, already applied in other to study areas in the scope of land use changes ( $N i$ et al., 2021). Yet, other multidisciplinary aspects must be considered in land-use changes, such as flood risk, drought, wildfires (Mishra et al., 2020).

\section{Conclusion}

The Ave River basin underwent landscape changes in the past decades that impacted stream water quality considerably. The effect of human activities was so dominant that could be considered a threat to water resources and watershed resilience. The association between 8 water quality parameters and 61 landscape metrics was measured by the Spearman's correlation rank during 26 hydrological years. The correlation analysis was combined with the assessment of landscape change tendencies in space and time, with the purpose to identify landscape characteristics requiring intervention in order to improve the Ave River Basin water resources. The growth of agricultural and urban areas coupled with the decline of forested areas with high edge density were the most preoccupying results in that regard. At the same time, forestry contributed to improved water resources. The present study is an eyeopening contribution to expose interactions that occurred in this watershed and that can guide future studies. It was also a challenge for the local municipalities that are urged to interfere in the landscape changes that are threatening water quality.

\section{Conflict of interest statement}

The authors declare that there are no conflicts of interest regarding the publication of this paper.

\section{Acknowledgements}

For authors integrated in the CITAB research centre, this work was supported by National Funds by FCT - Portuguese Foundation for Science and Technology, under the project UIDB/04033/2020. The authors integrated in the CITAB research centre are also integrated in the Inov4Agro - Institute for Innovation, Capacity Building and Sustainability of Agrifood Production. The Inov4Agro is an Associate Laboratory composed of two R\&D units (CITAB \& GreenUPorto). For the author integrated in the CQVR, the research was additionally supported by National Funds by FCT - Portuguese Foundation for Science and Technology, under the project UIDB/QUI/00616/2020 and UIDP/00616/2020. Financial support was provided by the Portuguese Foundation for Science and Technology (FCT), Ministry of Science, Technology, and Higher Education (MCTES), European Social Fund (FSE) through NORTE 2020 (North Regional Operational Program 2014/2020) and European Union (EU) to António Fernandes (Grant: SFRH/BD/146151/2019).

Appendix A. number of sampling sites for each SWP and HY

See Appendix Table A.1. 
Table A.1

Chosen SWP and respective number of sampling sites for each HY.

\begin{tabular}{|c|c|c|c|c|c|c|c|c|}
\hline & $\begin{array}{l}\text { Total suspended } \\
\text { solids }\end{array}$ & Conductivity & $\begin{array}{l}\text { Ammoniacal } \\
\text { nitrogen }\end{array}$ & $\begin{array}{l}\text { Total } \\
\text { nitrate }\end{array}$ & $\begin{array}{l}\text { Total } \\
\text { orthophosphate }\end{array}$ & $\begin{array}{l}\text { Biological oxygen } \\
\text { demand }\end{array}$ & $\begin{array}{l}\text { Chemical oxygen } \\
\text { demand }\end{array}$ & $\begin{array}{l}\text { Dissolved } \\
\text { oxygen }\end{array}$ \\
\hline 1988-1989 & 3 & 3 & 3 & 0 & 0 & 3 & 0 & 3 \\
\hline 1989-1990 & 6 & 6 & 6 & 6 & 6 & 6 & 6 & 6 \\
\hline 1990-1991 & 6 & 6 & 6 & 6 & 6 & 6 & 6 & 6 \\
\hline 1991-1992 & 6 & 6 & 6 & 6 & 6 & 6 & 6 & 6 \\
\hline 1992-1993 & 1 & 3 & 3 & 3 & 3 & 1 & 3 & 3 \\
\hline 1993-1994 & 15 & 15 & 15 & 15 & 15 & 15 & 15 & 15 \\
\hline 1994-1995 & 15 & 15 & 15 & 15 & 15 & 15 & 15 & 15 \\
\hline 1995-1996 & 15 & 15 & 15 & 15 & 15 & 15 & 15 & 15 \\
\hline 1996-1997 & 16 & 17 & 17 & 17 & 17 & 16 & 17 & 17 \\
\hline 1997-1998 & 17 & 17 & 17 & 17 & 17 & 17 & 17 & 17 \\
\hline 1998-1999 & 20 & 20 & 20 & 20 & 20 & 20 & 20 & 20 \\
\hline 1999-2000 & 18 & 18 & 18 & 18 & 16 & 18 & 17 & 18 \\
\hline 2000-2001 & 10 & 7 & 10 & 10 & 7 & 10 & 7 & 10 \\
\hline 2001-2002 & 11 & 9 & 9 & 8 & 8 & 9 & 8 & 11 \\
\hline $2002-2003$ & 12 & 9 & 9 & 9 & 8 & 9 & 8 & 12 \\
\hline 2003-2004 & 12 & 9 & 9 & 9 & 8 & 9 & 8 & 12 \\
\hline 2004-2005 & 13 & 13 & 13 & 12 & 12 & 13 & 12 & 13 \\
\hline 2005-2006 & 13 & 13 & 13 & 12 & 12 & 13 & 12 & 10 \\
\hline 2006-2007 & 14 & 14 & 14 & 14 & 13 & 14 & 13 & 14 \\
\hline 2007-2008 & 14 & 14 & 14 & 12 & 12 & 14 & 12 & 14 \\
\hline 2008-2009 & 27 & 24 & 28 & 28 & 22 & 23 & 22 & 23 \\
\hline 2009-2010 & 31 & 31 & 31 & 30 & 25 & 31 & 30 & 31 \\
\hline 2010-2011 & 20 & 21 & 23 & 23 & 16 & 22 & 19 & 23 \\
\hline 2011-2012 & 19 & 18 & 17 & 16 & 16 & 19 & 16 & 19 \\
\hline 2012-2013 & 17 & 17 & 17 & 17 & 16 & 17 & 17 & 17 \\
\hline 2013-2014 & 28 & 28 & 28 & 28 & 13 & 28 & 15 & 28 \\
\hline 2014-2015 & 29 & 29 & 29 & 29 & 6 & 29 & 8 & 29 \\
\hline 2015-2016 & 8 & 13 & 8 & 9 & 6 & 9 & 8 & 9 \\
\hline 2016-2017 & 8 & 8 & 8 & 8 & 0 & 8 & 0 & 8 \\
\hline 2017-2018 & 0 & 0 & 0 & 0 & 0 & 0 & 0 & 0 \\
\hline
\end{tabular}

Appendix B. Intervention analysis

See Appendix Table B.1.

Table B.1

Intervention analysis.

\begin{tabular}{|c|c|c|c|c|c|c|c|c|c|c|}
\hline \multirow[t]{2}{*}{ Metric } & \multirow[t]{2}{*}{ Units } & \multicolumn{5}{|c|}{ Metric value } & \multirow[t]{2}{*}{ Variation } & \multicolumn{2}{|c|}{ Impact on WQ } & \multirow{2}{*}{$\begin{array}{l}\text { Intervention } \\
\text { Priority }\end{array}$} \\
\hline & & 1995 & 2007 & 2010 & 2015 & 2018 & & Decrease & Increase & \\
\hline ca_(AGR) & $\mathrm{km}^{2}$ & $8.15 E+02$ & $7.35 \mathrm{E}+02$ & $7.35 \mathrm{E}+02$ & $7.63 \mathrm{E}+02$ & $8.76 \mathrm{E}+02$ & $11.60 \%$ & 118 & 0 & short-term \\
\hline ca_(ART) & & $3.85 \mathrm{E}+02$ & $4.78 \mathrm{E}+02$ & \#\#\#\#\# & \#\#\#\#\# & $4.47 \mathrm{E}+02$ & $-2.10 \%$ & 145 & 0 & long-term \\
\hline ca_(FOR) & & $1.27 \mathrm{E}+03$ & $1.25 \mathrm{E}+03$ & $1.25 \mathrm{E}+03$ & $1.21 \mathrm{E}+03$ & $1.14 \mathrm{E}+03$ & $-6.50 \%$ & 59 & 0 & \\
\hline ca_(WAB) & & \#\#\#\#\# & $8.85 \mathrm{E}+00$ & $8.85 \mathrm{E}+00$ & \#\#\#\#\# & $6.76 \mathrm{E}+00$ & $-19.90 \%$ & 42 & 1 & \\
\hline npc_(AGR) & count & $5.40 \mathrm{E}+03$ & $5.64 \mathrm{E}+03$ & $5.64 \mathrm{E}+03$ & $5.89 \mathrm{E}+03$ & $3.15 \mathrm{E}+03$ & $-38.80 \%$ & 114 & 0 & monitoring \\
\hline npc_(ART) & & $2.85 \mathrm{E}+03$ & $5.30 \mathrm{E}+03$ & $5.33 \mathrm{E}+03$ & $5.03 E+03$ & \#\#\#\#\# & $-26.20 \%$ & 125 & 0 & monitoring \\
\hline npc_(FOR) & & $7.35 \mathrm{E}+03$ & \#\#\#\#\# & $1.02 \mathrm{E}+04$ & $7.05 E+03$ & \#\#\#\#\# & $-43.50 \%$ & 69 & 0 & \\
\hline npc_(WAB) & & $6.50 \mathrm{E}+01$ & $7.10 \mathrm{E}+01$ & $7.10 \mathrm{E}+01$ & $7.20 \mathrm{E}+01$ & $4.25 \mathrm{E}+01$ & $-33.90 \%$ & 46 & 1 & \\
\hline $\mathrm{pz}_{-}(\mathrm{AGR})$ & $\%$ & $3.29 \mathrm{E}+01$ & $2.97 \mathrm{E}+01$ & $2.97 \mathrm{E}+01$ & $3.08 \mathrm{E}+01$ & $3.54 \mathrm{E}+01$ & $11.60 \%$ & 135 & 0 & short-term \\
\hline pz_(ART) & & $1.56 \mathrm{E}+01$ & $1.93 \mathrm{E}+01$ & $1.95 \mathrm{E}+01$ & $1.99 \mathrm{E}+01$ & $1.81 \mathrm{E}+01$ & $-2.10 \%$ & 163 & 0 & long-term \\
\hline pz_(FOR) & & $5.11 \mathrm{E}+01$ & $5.06 \mathrm{E}+01$ & $5.04 \mathrm{E}+01$ & $4.89 \mathrm{E}+01$ & $4.62 \mathrm{E}+01$ & $-6.50 \%$ & 0 & 163 & long-term \\
\hline $\mathrm{pz}_{-}(\mathrm{WAB})$ & & 3.57E-01 & $3.58 \mathrm{E}-01$ & $3.58 \mathrm{E}-01$ & $3.59 \mathrm{E}-01$ & 2.73E-01 & $-19.90 \%$ & 10 & 11 & \\
\hline tc_edge_(ALL) & $\mathrm{km}^{2}$ & \#\#\#\#\# & $3.91 \mathrm{E}+04$ & \#\#\#\#\# & \#\#\#\#\# & \#\#\#\#\# & $-28.50 \%$ & 93 & 0 & \\
\hline tc_edge_(AGR) & & $1.20 \mathrm{E}+04$ & $1.16 \mathrm{E}+04$ & $1.15 \mathrm{E}+04$ & $1.20 \mathrm{E}+04$ & \#\#\#\#\# & $-25.00 \%$ & 116 & 0 & monitoring \\
\hline tc_edge_(ART) & & $7.05 E+03$ & \#\#\#\#\# & $9.91 \mathrm{E}+03$ & \#\#\#\#\# & $6.41 \mathrm{E}+03$ & $-25.50 \%$ & 135 & 0 & monitoring \\
\hline tc_edge_(FOR) & & $1.50 \mathrm{E}+04$ & $1.73 \mathrm{E}+04$ & $1.74 \mathrm{E}+04$ & $1.43 \mathrm{E}+04$ & \#\#\#\#\# & $-32.60 \%$ & 59 & 0 & \\
\hline tc_edge_(WAB) & & \#\#\#\#\# & $3.21 \mathrm{E}+02$ & $3.21 \mathrm{E}+02$ & \#\#\#\#\# & $1.86 \mathrm{E}+02$ & $-36.60 \%$ & 43 & 1 & \\
\hline ed_(ALL) & $\mathrm{km}^{2} /$ hectare & $1.39 \mathrm{E}+03$ & $1.58 \mathrm{E}+03$ & $1.58 \mathrm{E}+03$ & $1.47 \mathrm{E}+03$ & $1.01 \mathrm{E}+03$ & $-28.50 \%$ & 103 & 0 & \\
\hline ed_(AGR) & & $4.85 \mathrm{E}+02$ & $4.67 \mathrm{E}+02$ & $4.67 \mathrm{E}+02$ & \#\#\#\#\# & $3.35 \mathrm{E}+02$ & $-25.00 \%$ & 150 & 0 & monitoring \\
\hline ed_(ART) & & $2.85 \mathrm{E}+02$ & $3.97 \mathrm{E}+02$ & \#\#\#\#\# & $3.97 \mathrm{E}+02$ & $2.59 \mathrm{E}+02$ & $-25.50 \%$ & 158 & 0 & monitoring \\
\hline ed_(FOR) & & $6.05 \mathrm{E}+02$ & $7.01 \mathrm{E}+02$ & $7.04 \mathrm{E}+02$ & $5.79 \mathrm{E}+02$ & \#\#\#\#\# & $-32.60 \%$ & 0 & 146 & short-term \\
\hline ed_(WAB) & & $1.29 \mathrm{E}+01$ & $1.30 \mathrm{E}+01$ & $1.30 \mathrm{E}+01$ & $1.30 \mathrm{E}+01$ & $7.53 E+00$ & $-36.60 \%$ & 34 & 0 & \\
\hline shdi_(ALL) & & $1.02 \mathrm{E}+00$ & $1.04 \mathrm{E}+00$ & $1.04 \mathrm{E}+00$ & $1.05 \mathrm{E}+00$ & $1.04 \mathrm{E}+00$ & $0.10 \%$ & 163 & 0 & long-term \\
\hline el_(ART)_with_(AGR) & $\mathrm{km}$ & \#\#\#\#\# & $4.76 \mathrm{E}+03$ & $4.77 \mathrm{E}+03$ & $5.01 \mathrm{E}+03$ & $3.21 \mathrm{E}+03$ & $-28.10 \%$ & 128 & 0 & monitoring \\
\hline el_(FOR)_with_(AGR) & & $4.75 \mathrm{E}+03$ & \#\#\#\#\# & $4.35 \mathrm{E}+03$ & \#\#\#\#\# & \#\#\#\#\# & $-23.30 \%$ & 74 & 0 & \\
\hline el_(WAB)_with_(AGR) & & $1.17 \mathrm{E}+02$ & $1.05 \mathrm{E}+02$ & $1.05 \mathrm{E}+02$ & $1.12 \mathrm{E}+02$ & $6.10 \mathrm{E}+01$ & $-39.20 \%$ & 68 & 1 & \\
\hline el_(FOR)_with_(ART) & & \#\#\#\#\# & $3.21 \mathrm{E}+03$ & \#\#\#\#\# & \#\#\#\#\# & $1.94 \mathrm{E}+03$ & $-29.20 \%$ & 129 & 0 & monitoring \\
\hline el_(WAB)_with_(ART) & & $2.92 \mathrm{E}+01$ & $3.43 E+01$ & $3.44 \mathrm{E}+01$ & $3.51 \mathrm{E}+01$ & $2.10 \mathrm{E}+01$ & $-31.70 \%$ & 48 & 1 & \\
\hline
\end{tabular}


Table B.1 (continued)

\begin{tabular}{|c|c|c|c|c|c|c|c|c|c|c|}
\hline \multirow[t]{2}{*}{ Metric } & \multirow[t]{2}{*}{ Units } & \multicolumn{5}{|c|}{ Metric value } & \multirow[t]{2}{*}{ Variation } & \multicolumn{2}{|c|}{ Impact on WQ } & \multirow{2}{*}{$\begin{array}{l}\text { Intervention } \\
\text { Priority }\end{array}$} \\
\hline & & 1995 & 2007 & 2010 & 2015 & 2018 & & Decrease & Increase & \\
\hline el_(WAB)_with_(FOR) & & $1.13 \mathrm{E}+02$ & $1.21 \mathrm{E}+02$ & $1.21 \mathrm{E}+02$ & $1.14 \mathrm{E}+02$ & $7.43 \mathrm{E}+01$ & $-31.60 \%$ & 39 & 1 & \\
\hline cce_(ART)_with_(AGR) & $\%$ & $3.83 \mathrm{E}+01$ & $4.11 \mathrm{E}+01$ & $4.13 \mathrm{E}+01$ & $4.19 \mathrm{E}+01$ & $3.57 \mathrm{E}+01$ & $-10.00 \%$ & 163 & 0 & monitoring \\
\hline cce_(FOR)_with_(AGR) & & $3.96 \mathrm{E}+01$ & $3.78 \mathrm{E}+01$ & $3.76 \mathrm{E}+01$ & $3.68 \mathrm{E}+01$ & $3.97 \mathrm{E}+01$ & $3.60 \%$ & 0 & 149 & long-term \\
\hline cce_(WAB)_with_(AGR) & & 9.77E-01 & 9.12E-01 & $9.13 \mathrm{E}-01$ & 9.37E-01 & 6.19E-01 & $-28.90 \%$ & 38 & 1 & \\
\hline cce_(AGR)_with_(ART) & & $6.53 \mathrm{E}+01$ & $4.84 \mathrm{E}+01$ & $4.81 \mathrm{E}+01$ & $5.11 \mathrm{E}+01$ & $5.37 \mathrm{E}+01$ & $0.80 \%$ & 0 & 80 & \\
\hline cce_(FOR)_with_(ART) & & $3.30 \mathrm{E}+01$ & $3.26 \mathrm{E}+01$ & $3.26 \mathrm{E}+01$ & $3.07 \mathrm{E}+01$ & $2.83 \mathrm{E}+01$ & $-9.90 \%$ & 0 & 19 & \\
\hline cce_(WAB)_with_(ART) & & 4.14E-01 & 3.49E-01 & $3.48 \mathrm{E}-01$ & 3.57E-01 & $2.76 \mathrm{E}-01$ & $-20.90 \%$ & 50 & 0 & \\
\hline cce_(AGR)_with_(FOR) & & $3.17 \mathrm{E}+01$ & $2.52 \mathrm{E}+01$ & $2.49 \mathrm{E}+01$ & $3.07 \mathrm{E}+01$ & $3.59 \mathrm{E}+01$ & $21.00 \%$ & 39 & 0 & \\
\hline cce_(ART)_with_(FOR) & & $1.55 \mathrm{E}+01$ & $1.85 \mathrm{E}+01$ & $1.85 \mathrm{E}+01$ & $2.11 \mathrm{E}+01$ & $1.70 \mathrm{E}+01$ & $-6.10 \%$ & 148 & 0 & long-term \\
\hline cce_(WAB)_with_(FOR) & & 7.56E-01 & $6.96 \mathrm{E}-01$ & $6.92 \mathrm{E}-01$ & 7.97E-01 & $6.20 \mathrm{E}-01$ & $-12.90 \%$ & 18 & 3 & \\
\hline cce_(AGR)_with_(WAB) & & $3.66 \mathrm{E}+01$ & $3.29 \mathrm{E}+01$ & $3.29 \mathrm{E}+01$ & $3.48 \mathrm{E}+01$ & $3.65 \mathrm{E}+01$ & $5.10 \%$ & 11 & 1 & \\
\hline cce_(ART)_with_(WAB) & & $9.11 \mathrm{E}+00$ & $1.07 \mathrm{E}+01$ & $1.07 \mathrm{E}+01$ & $1.09 \mathrm{E}+01$ & $1.15 \mathrm{E}+01$ & $8.30 \%$ & 51 & 0 & \\
\hline cce_(FOR)_with_(WAB) & & $3.53 \mathrm{E}+01$ & $3.76 \mathrm{E}+01$ & $3.76 \mathrm{E}+01$ & $3.55 \mathrm{E}+01$ & $4.30 \mathrm{E}+01$ & $13.70 \%$ & 1 & 13 & \\
\hline ci_np_(AGR) & count & $3.77 \mathrm{E}+04$ & $3.77 \mathrm{E}+04$ & \#\#\#\#\# & $5.52 \mathrm{E}+04$ & $2.70 \mathrm{E}+04$ & $-34.90 \%$ & 105 & 0 & monitoring \\
\hline ci_np_(ART) & & \#\#\#\#\# & \#\#\#\#\# & \#\#\#\#\# & $3.65 \mathrm{E}+04$ & \#\#\#\#\# & $-29.10 \%$ & 123 & 0 & monitoring \\
\hline ci_np_(FOR) & & $3.21 \mathrm{E}+04$ & $3.21 \mathrm{E}+04$ & $4.37 \mathrm{E}+04$ & \#\#\#\#\# & \#\#\#\#\# & $-29.70 \%$ & 133 & 0 & monitoring \\
\hline ci_np_(WAB) & & $1.40 \mathrm{E}+01$ & $1.40 \mathrm{E}+01$ & $2.40 \mathrm{E}+01$ & $2.40 \mathrm{E}+01$ & $1.20 \mathrm{E}+01$ & $-31.80 \%$ & 104 & 0 & monitoring \\
\hline ci_pa_(AGR) & $\mathrm{km}^{2}$ & $7.14 \mathrm{E}+02$ & $7.14 \mathrm{E}+02$ & $7.87 \mathrm{E}+02$ & \#\#\#\#\# & $4.57 \mathrm{E}+02$ & $-34.90 \%$ & 101 & 0 & \\
\hline ci_pa_(ART) & & \#\#\#\#\# & \#\#\#\#\# & $5.41 \mathrm{E}+02$ & $5.45 \mathrm{E}+02$ & $3.16 \mathrm{E}+02$ & $-33.80 \%$ & 135 & 0 & monitoring \\
\hline ci_pa_(FOR) & & $5.82 \mathrm{E}+02$ & $5.82 \mathrm{E}+02$ & $6.81 \mathrm{E}+02$ & \#\#\#\#\# & \#\#\#\#\# & $-33.60 \%$ & 119 & 0 & monitoring \\
\hline ci_pa_(WAB) & & $2.05 \mathrm{E}-01$ & 2.05E-01 & $3.45 \mathrm{E}-01$ & $3.45 \mathrm{E}-01$ & $1.73 \mathrm{E}-01$ & $-32.10 \%$ & 104 & 0 & monitoring \\
\hline ci_pp_(AGR) & $\%$ & $2.88 \mathrm{E}+01$ & $2.88 \mathrm{E}+01$ & $3.18 \mathrm{E}+01$ & $3.38 \mathrm{E}+01$ & $1.85 \mathrm{E}+01$ & $-34.90 \%$ & 156 & 0 & monitoring \\
\hline ci_pp_(ART) & & $1.99 \mathrm{E}+01$ & $1.99 \mathrm{E}+01$ & $2.19 \mathrm{E}+01$ & $2.20 \mathrm{E}+01$ & $1.28 \mathrm{E}+01$ & $-33.80 \%$ & 147 & 0 & monitoring \\
\hline ci_pp_(FOR) & & $2.35 \mathrm{E}+01$ & $2.35 \mathrm{E}+01$ & $2.75 \mathrm{E}+01$ & $2.68 \mathrm{E}+01$ & $1.55 \mathrm{E}+01$ & $-33.60 \%$ & 68 & 1 & \\
\hline ci_pp_(WAB) & & $8.00 \mathrm{E}-03$ & $8.00 \mathrm{E}-03$ & $1.40 \mathrm{E}-02$ & $1.40 \mathrm{E}-02$ & $7.00 \mathrm{E}-03$ & $-31.40 \%$ & 92 & 0 & \\
\hline ci_ca_(AGR) & $\mathrm{km}^{2}$ & \#\#\#\#\# & \#\#\#\#\# & \#\#\#\#\# & $3.73 \mathrm{E}+02$ & $2.15 \mathrm{E}+02$ & $-33.40 \%$ & 98 & 0 & \\
\hline ci_ca_(ART) & & \#\#\#\#\# & \#\#\#\#\# & \#\#\#\#\# & $3.61 \mathrm{E}+02$ & $2.05 \mathrm{E}+02$ & $-35.40 \%$ & 135 & 0 & monitoring \\
\hline ci_ca_(FOR) & & $2.70 \mathrm{E}+02$ & $2.70 \mathrm{E}+02$ & $3.12 \mathrm{E}+02$ & $3.05 \mathrm{E}+02$ & $1.87 \mathrm{E}+02$ & $-30.60 \%$ & 116 & 0 & monitoring \\
\hline ci_ca_(WAB) & & 2.33E-01 & 2.33E-01 & $4.68 \mathrm{E}-01$ & $4.68 \mathrm{E}-01$ & $2.34 \mathrm{E}-01$ & $-28.50 \%$ & 104 & 0 & monitoring \\
\hline ci_cp_(AGR) & $\%$ & $1.34 \mathrm{E}+01$ & $1.34 \mathrm{E}+01$ & $1.47 \mathrm{E}+01$ & $1.51 \mathrm{E}+01$ & \#\#\#\#\# & $-33.40 \%$ & 140 & 0 & monitoring \\
\hline ci_cp_(ART) & & $1.33 \mathrm{E}+01$ & $1.33 \mathrm{E}+01$ & $1.45 \mathrm{E}+01$ & $1.46 \mathrm{E}+01$ & $8.27 \mathrm{E}+00$ & $-35.40 \%$ & 144 & 0 & monitoring \\
\hline ci_cp_(FOR) & & $1.09 \mathrm{E}+01$ & $1.09 \mathrm{E}+01$ & $1.26 \mathrm{E}+01$ & $1.23 \mathrm{E}+01$ & $7.54 \mathrm{E}+00$ & $-30.60 \%$ & 112 & 0 & monitoring \\
\hline ci_cp_(WAB) & & $9.00 \mathrm{E}-03$ & $9.00 \mathrm{E}-03$ & $1.90 \mathrm{E}-02$ & $1.90 \mathrm{E}-02$ & $9.50 \mathrm{E}-03$ & $-27.50 \%$ & 104 & 0 & monitoring \\
\hline
\end{tabular}

\section{Appendix C. Supporting information compact-standard}

Supplementary data associated with this article can be found in the online version at doi:10.1016/j.landusepol.2021.105679.

\section{References}

Acuña-Alonso, C., Fernandes, A.C.P., Álvarez, X., Valero, E., Pacheco, F.A.L., Varandas, S.D.G.P., Terêncio, D.P.S., Fernandes, L.F.S., 2021. Water security and watershed management assessed through the modelling of hydrology and ecological integrity: a study in the Galicia-Costa (NW Spain). Sci. Total Environ. 759, 143905 https://doi.org/10.1016/j.scitotenv.2020.143905.

Adamczyk, J., Tiede, D., 2017. ZonalMetrics - a Python toolbox for zonal landscape structure analysis. Comput. Geosci. 99, 91-99. https://doi.org/10.1016/J. CAGEO.2016.11.005.

Ahearn, D.S., Sheibley, R.W., Dahlgren, R.A., Anderson, M., Johnson, J., Tate, K.W., 2005. Land use and land cover influence on water quality in the last free-flowing river draining the western Sierra Nevada, California. J. Hydrol. 313, 234-247. https://doi.org/10.1016/j.jhydrol.2005.02.038.

Allan, J.D., Erickson, D.L., Fay, J., 1997. The influence of catchment land use on stream integrity across multiple spatial scales. Freshw. Biol. 37, 149-161. https://doi.org/ 10.1046/j.1365-2427.1997.d01-546.x.

Altieri, M. a, Nicholls, C.I., 2012. Sustainable Agriculture Reviews, Sustainable Agriculture Reviews. https://doi.org/10.1007/978-94-007-5449-2.

Alves, C., Boaventura, R., Soares, H., 2009. Evaluation of heavy metals pollution loadings in the sediments of the ave river basin (Portugal). Soil Sediment Contam. 18, 603-618. https://doi.org/10.1080/15320380903113568.

Amaral, Y.T., Santos, E.M., dos, Ribeiro, M.C., Barreto, L., 2019. Landscape structural analysis of the Lençóis Maranhenses national park: implications for conservation. J. Nat. Conserv. 51, 125725 https://doi.org/10.1016/j.jnc.2019.125725.

Amiri, B.J., Nakane, K., 2008. Entire catchment and buffer zone approaches to modeling linkage between river water quality and land cover - a case study of Yamaguchi Prefecture. Jpn. Chin. Geogr. Sci. 18, 85-92. https://doi.org/10.1007/s11769-0080085-6.

Araújo, M.F., Valério, P., Jouanneau, J.M., 1998. Heavy metal assessment in sediments of the ave river basin (Portugal) by energy-dispersive X-ray fluorescence spectrometry. X-Ray Spectrom. 27, 305-312. https://doi.org/10.1002/(SICI)1097-4539(199809/ 10) $27: 5<305::$ AID-XRS275>3.0.CO;2-7.

Araújo Costa, R.C., Pereira, G.T., Tarlé Pissarra, T.C., Silva Siqueira, D., Sanches Fernandes, L.F., Vasconcelos, V., Fernandes, L.A., Pacheco, F.A.L., 2019. Land capability of multiple-landform watersheds with environmental land use conflicts. Land Use Policy 81, 689-704. https://doi.org/10.1016/J. LANDUSEPOL.2018.11.041.

Bartram, Jamie, 1996. Chapter 3 - DESIGNING A MONITORING PROGRAMME. Water Quality Monitoring- A practical guide to the design and implementation of freshwater quality studies and monitoring programmes, 1st. CRC Press, USA.

Binkley, D., Ice, G.G., Kaye, J., Williams, C.A., 2004. Nitrogen and phosphorus concentrations in forest streams of the United States. J. Am. Water Resour. Assoc. 40, 1277-1291. https://doi.org/10.1111/j.1752-1688.2004.tb01586.x.

Bolinches, A., Paredes-Arquiola, J., Garrido, A., De Stefano, L., 2020. A comparative analysis of the application of water quality exemptions in the European Union: the case of nitrogen. Sci. Total Environ. 739, 139891 https://doi.org/10.1016/j. scitotenv.2020.139891.

Bonansea, M., Bazán, R., Germán, A., Ferral, A., Beltramone, G., Cossavella, A., Pinotti, L., 2021. Assessing land use and land cover change in Los Molinos reservoir watershed and the effect on the reservoir water quality. J. South Am. Earth Sci. 108, 103243 https://doi.org/10.1016/j.jsames.2021.103243.

Bu, H., Meng, W., Zhang, Y., Wan, J., 2014. Relationships between land use patterns and water quality in the Taizi River basin, China. Ecol. Indic. 41, 187-197. https://doi. org/10.1016/J.ECOLIND.2014.02.003.

Buonocore, C., Gomiz Pascual, J.J., Pérez Cayeiro, M.L., Mañanes Salinas, R., Bruno Mejías, M., 2021. Modelling the impacts of climate and land use changes on water quality in the Guadiana basin and the adjacent coastal area. Sci. Total Environ. 776, 146034 https://doi.org/10.1016/j.scitotenv.2021.146034.

Camara, M., Jamil, N.R., Abdullah, A.F. Bin, Hashim, R. binti, Aliyu, A.G., 2020. Economic and efficiency based optimisation of water quality monitoring network for land use impact assessment. Sci. Total Environ. 737, 139800 https://doi.org/ 10.1016/j.scitotenv.2020.139800.

Carvalho, L., Mackay, E.B., Cardoso, A.C., Baattrup-Pedersen, A., Birk, S., Blackstock, K. L., Borics, G., Borja, A., Feld, C.K., Ferreira, M.T., Globevnik, L., Grizzetti, B., Hendry, S., Hering, D., Kelly, M., Langaas, S., Meissner, K., Panagopoulos, Y., Penning, E., Rouillard, J., Sabater, S., Schmedtje, U., Spears, B.M., Venohr, M., van de Bund, W., Solheim, A.L., 2019. Protecting and restoring Europe's waters: an analysis of the future development needs of the Water Framework Directive. Sci. Total Environ. 658, 1228-1238. https://doi.org/10.1016/j.scitotenv.2018.12.255.

Chang, H., Makido, Y., Foster, E., 2021. Effects of land use change, wetland fragmentation, and best management practices on total suspended sediment concentrations in an urbanizing Oregon watershed, USA. J. Environ. Manag. 282, 111962 https://doi.org/10.1016/j.jenvman.2021.111962.

Clarke, J., Kelly-Quinn, M., Blacklocke, S., Bruen, M., 2015. The effect of forest windrowing on physico-chemical water quality in Ireland. Sci. Total Environ. 514, 155-169. https://doi.org/10.1016/j.scitotenv.2015.01.107. 
Clément, F., Ruiz, J., Rodríguez, M.A., Blais, D., Campeau, S., 2017. Landscape diversity and forest edge density regulate stream water quality in agricultural catchments. Ecol. Indic. 72, 627-639. https://doi.org/10.1016/j.ecolind.2016.09.001.

Cortes, R., Hughes, S., Coimbra, A., Monteiro, S., Pereira, V., Lopes, M., Pereira, S., Pinto, A., Sampaio, A., Santos, C., Carrola, J., de Jesus, J., Varandas, S., 2016. A multiple index integrating different levels of organization. Ecotoxicol. Environ. Saf. 132, 270-278. https://doi.org/10.1016/j.ecoenv.2016.06.001.

Costa, F., 2008. Hidro-conflitos na bacia hidrográfica do rio Ave - uma análise a partir das transgressões cometidas no período 1902-1973, Actas do XI Colóquio Ibérico de Geografia.

Costa, F., Alonso, J., Fernandes, S., 2012. Avaliação do potencial de valorização dos ecossistemas fluviais - aplicação ao Caso de Estudo do Rio Ave. Rev. Geonorte 3, 643-655.

Decatanzaro, R., Cvetkovic, M., Chow-Fraser, P., 2009. The relative importance of road density and physical watershed features in determining coastal marsh water quality in georgian bay. Environ. Manag. 44, 456-467. https://doi.org/10.1007/s00267 009-9338-0.

Dellapenna, J.W., Gupta, J., 2009. The evolution of the law and politics of water. Evol. Law Polit. Water 3-19. https://doi.org/10.1007/978-1-4020-9867-3.

DGT, 2018. Direcção geral do território [WWW Document]. Cart. Uso e Ocupação do solo. URL http://www.dgterritorio.pt/. (Accessed 4 December 2020).

Ding, J., Jiang, Y., Liu, Q., Hou, Z., Liao, J., Fu, L., Peng, Q., 2016. Influences of the land use pattern on water quality in low-order streams of the Dongjiang River basin, China: a multi-scale analysis. Sci. Total Environ. 551-552. https://doi.org/10.1016/ j.scitotenv.2016.01.162.

Dodds, W.K., Oakes, R.M., 2008. Headwater influences on downstream water quality. Environ. Manag. 41, 367-377. https://doi.org/10.1007/s00267-007-9033-y.

Dow, C.L., Arscott, D.B., Newbold, J.D., 2006. Relating major ions and nutrients to watershed conditions across a mixed-use, water-supply watershed. J. North Am. Benthol. Soc. 25, 887-911. https://doi.org/10.1899/0887-3593(2006)025[0887: RMIANT]2.0.CO;2.

Duffy, C., O’Donoghue, C., Ryan, M., Kilcline, K., Upton, V., Spillane, C., 2020. The impact of forestry as a land use on water quality outcomes: an integrated analysis. For. Policy Econ. 116, 102185 https://doi.org/10.1016/j.forpol.2020.102185.

Dunck, B., Lima-Fernandes, E., Cássio, F., Cunha, A., Rodrigues, L., Pascoal, C., 2015. Responses of primary production, leaf litter decomposition and associated communities to stream eutrophication. Environ. Pollut. 202, 32-40. https://doi.org/ 10.1016/j.envpol.2015.03.014.

EEA, 2021. Data and maps - European Environment Agency [WWW Document]. URL https://www.eea.europa.eu/data-and-maps. (Accessed 12 December 2018).

Eom, H., Park, C., 2021. Investigation of characteristics of effluent DON derived from conventional activated sludge (CAS) and predenitrification biological removal (BNR): in terms of proteins and humic substances. Environ. Res. 196, 110912 https://doi.org/10.1016/j.envres.2021.110912.

ESRI, 2012b. ArcHydro Tools for ArcGIS 10 - Tutorial.

ESRI, 2012a. ArcMap 10.1. Environ. Syst. Resour. Inst.

Fernandes, A., Sanches Fernandes, L.F., Terêncio, D.P.S., Cortes, R.M.V., Pacheco, F.A.L., 2019b. Seasonal and Scale Effects of Anthropogenic Pressures on Water Quality and Ecological Integrity: A Study in the Sabor River Basin (NE Portugal) Using Partial Least Squares-Path Modeling. Water. https://doi.org/10.3390/w11091941.

Fernandes, A., Fernandes, L.F.S., Cortes, R.M.V., Pacheco, F.A.L., 2019a. The role of landscape configuration, season, and distance from contaminant sources on the degradation of stream water quality in urban catchments. Water 11, 20-25. https:// doi.org/10.3390/w11102025.

Fernandes, A.C.P., Sanches Fernandes, L.F., Moura, J.P., Cortes, R.M.V., Pacheco, F.A.L 2019. A structural equation model to predict macroinvertebrate-based ecological status in catchments influenced by anthropogenic pressures. Sci. Total Environ. 681, 242-257. https://doi.org/10.1016/J.SCITOTENV.2019.05.117.

Fernandes, A.C.P., Martins, L.M.O., Fernandes, L.F.S., Cortes, R.M.V., Pacheco, F.A.L., 2020. Exploring the effects of landscape metrics in water quality, Ave river basin case study. Int. J. Des. Nat. Ecodyn. 15, 65-72. https://doi.org/10.18280/ ijdne.150109.

Fernandes, L.F.S., Fernandes, A.C.P., Ferreira, A.R.L., Cortes, R.M.V., Pacheco, F.A.L., 2018. A partial least squares - path modeling analysis for the understanding of biodiversity loss in rural and urban watersheds in Portugal. Sci. Total Environ. 626, 1069-1085. https://doi.org/10.1016/J.SCITOTENV.2018.01.127.

Ferreira, A.R.L., Sanches Fernandes, L.F., Cortes, R.M.V., Pacheco, F.A.L., 2017. Assessing anthropogenic impacts on riverine ecosystems using nested partial least squares regression. Sci. Total Environ. 583, 466-477. https://doi.org/10.1016/j. scitotenv.2017.01.106.

Foley, J.A., DeFries, R., Asner, G.P., Barford, C., Bonan, G., Carpenter, S.R., Chapin, F.S., Coe, M.T., Daily, G.C., Gibbs, H.K, Helkowski, J.H., Holloway, T., Howard, E.A., Kucharik, C.J., Monfreda, C., Patz, J.A., Prentice, I.C., Ramankutty, N., Snyder, P.K., 2005. Global consequences of land use. Science (80-.). https://doi.org/10.1126/sc ience. 1111772 .

Fonseca, A., Boaventura, R.A.R., Vilar, V.J.P., 2018. Integrating water quality responses to best management practices in Portugal. Environ. Sci. Pollut. Res. https://doi. org/10.1007/s11356-017-0610-1.

Fonseca, A.R., Sanches Fernandes, L.F., Fontainhas-Fernandes, A., Monteiro, S.M., Pacheco, F.A.L., 2016. From catchment to fish: Impact of anthropogenic pressures on gill histopathology. Sci. Total Environ. 550, 972-986. https://doi.org/10.1016/j scitotenv. 2016.01.199.

Fonseca, A.R., Sanches Fernandes, L.F., Fontainhas-Fernandes, A., Monteiro, S.M., Pacheco, F.A.L., 2017. The impact of freshwater metal concentrations on the severity of histopathological changes in fish gills: a statistical perspective. Sci. Total Environ. 599-600, 217-226. https://doi.org/10.1016/j.scitotenv.2017.04.196.
Forman, R.T.T., 1999. Land mosaics: the ecology of landscapes and regions. NCASI Tech. Bull. 174. https://doi.org/10.2134/jeq1997.00472425002600030047x.

Garrett, K., 2013. Sustainable agriculture, in: Environmental Management in Practice: Compartments, Stressors and Sectors. pp. 166-178. https://doi.org/10.7591/c ornell/9781501743887.003.0006.

Gonçalves, E.P.R., Boaventura, R.A.R., Mouvet, C., 1992. Sediments and aquatic mosses as pollution indicators for heavy metals in the Ave river basin (Portugal). Sci. Total Environ. https://doi.org/10.1016/0048-9697(92)90410-T.

Gove, N.E., Edwards, R.T., Conquest, L.L., 2001. Effects of scale on land use and water quality relationships: a longitudinal basin-wide perspective. J. Am. Water Resour. Assoc. 37, 1721-1734. https://doi.org/10.1111/j.1752-1688.2001.tb03672.x.

Gu, Q., Hu, H., Ma, L., Sheng, L., Yang, S., Zhang, X., Zhang, M., Zheng, K., Chen, L., 2019. Characterising the spatial variations of the relationship between land use and surface water quality using self-organising map approach. Ecol. Indic. 102, 633-643. https://doi.org/10.1016/j.ecolind.2019.03.017.

Habibi, S., Asadi, N., 2011. Causes, results and methods of controlling urban sprawl, in: Procedia Engineering. https://doi.org/10.1016/j.proeng.2011.11.1996.

Hauke, J., Kossowski, T., 2011. Comparison of values of pearson's and spearman's correlation coefficients on the same sets of data. Quaest. Geogr. https://doi.org/10. 2478/v10117-011-0021-1.

Hayet, C., Saida, B.A., Youssef, T., Hédi, S., 2016. Study of biodegradability for municipal and industrial Tunisian wastewater by respirometric technique and batch reactor test. Sustain. Environ. Res. 26, 55-62. https://doi.org/10.1016/j.serj.2015.11.001.

Hill, A.R., 1996. Nitrate Removal in Stream Riparian Zones. J. Environ. Qual. https:// doi.org/10.2134/jeq1996.00472425002500040014x.

Hughes, A.O., Quinn, J.M., 2019. The effect of forestry management activities on stream water quality within a headwater plantation Pinus radiata forest. Ecol. Manag. 439, 41-54. https://doi.org/10.1016/j.foreco.2019.02.035.

Hunsaker, C.T., Levine, D.A., 1995. Hierarchical approaches to the study of water quality in rivers. Bioscience 45, 193-203. https://doi.org/10.2307/1312558.

Jayasumana, C., Fonseka, S., Fernando, A., Jayalth, K., Amarasinghe, M., Paranagma, P., 2014. Presence of arsenic in agrochemicals and their association with the agricultural chronic kidney disease in Sri Lanka. J. Toxicol. Health 104, 352-361.

Jesus, H. De, Sousa, R., Oliveira, R., Nery, F., 1999. A Componente Geográfica do SNIRH. IV SILUSBA.

Johnson, L.B., Richards, C., Host, G.E., Arthur, J.W., 1997. Landscape influences on water chemistry in Midwestern stream ecosystems. Freshw. Biol. https://doi.org/10. 1046/j.1365-2427.1997.d01-539.x.

Kang, C.H., Kwon, Y.J., So, J.S., 2016. Bioremediation of heavy metals by using bacterial mixtures. Ecol. Eng. https://doi.org/10.1016/j.ecoleng.2016.01.023.

King, R.S., Baker, M.E., Whigham, D.F., Weller, D.E., Jordan, T.E., Kazyak, P.F., Hurd, M. K., 2005. Spatial considerations for linking watershed land cover to ecological indicators in streams. Ecol. Appl. 15, 137-153. https://doi.org/10.1890/04-0481.

Lalwani, J., Gupta, A., Thatikonda, S., Subrahmanyam, C., 2020. An industrial insight on treatment strategies of the pharmaceutical industry effluent with varying qualitative characteristics. J. Environ. Chem. Eng. 8, 104190 https://doi.org/10.1016/j. jece.2020.104190.

Larsen, S., Bruno, M.C., Vaughan, I.P., Zolezzi, G., 2019. Testing the river continuum concept with geostatistical stream-network models. Ecol. Complex. 39, 100773 https://doi.org/10.1016/j.ecocom.2019.100773.

Lee, S.W., Hwang, S.J., Lee, S.B., Hwang, H.S., Sung, H.C., 2009. Landscape ecological approach to the relationships of land use patterns in watersheds to water quality characteristics. Landsc. Urban Plan. 92, 80-89. https://doi.org/10.1016/j. landurbplan.2009.02.008.

Lenat, D.R., Crawford, J.K., 1994. Effects of land use on water quality and aquatic biota of three North Carolina Piedmont streams. Hydrobiologia. https://doi.org /10.1007/BF00021291.

Li, S., Gu, S., Tan, X., Zhang, Q., 2009. Water quality in the upper Han River basin, China: the impacts of land use/land cover in riparian buffer zone. J. Hazard. Mater. 165, 317-324. https://doi.org/10.1016/j.jhazmat.2008.09.123.

Li, S., Zhang, Y., Zhang, Q., 2012. Interaction of landscape setting and stream flow seasonality on nitrogen concentrations in a subtropical river, China. Acta Oecol. 44, 38-45. https://doi.org/10.1016/J.ACTAO.2011.08.005.

Li, Z., Luan, W., Zhang, Z., Su, M., 2020. Relationship between urban construction land expansion and population/economic growth in Liaoning Province, China. Land Use Policy 99, 105022. https://doi.org/10.1016/j.landusepol.2020.105022.

Long, B.T., 2020. Inverse algorithm for Streeter-Phelps equation in water pollution control problem. Math. Comput. Simul. 171, 119-126. https://doi.org/10.1016/j. matcom.2019.12.005.

Long, K., Omrani, H., Pijanowski, B.C., 2020. Impact of local payments for ecosystem services on land use in a developed area of China: a qualitative analysis based on an integrated conceptual framework. Land Use Policy 96, 104716. https://doi.org/ 10.1016/j.landusepol.2020.104716.

Łowicki, D., 2012. Prediction of flowing water pollution on the basis of landscape metrics as a tool supporting delimitation of nitrate vulnerable zones. Ecol. Indic. 23, 27-33. https://doi.org/10.1016/j.ecolind.2012.03.004.

Madsen, J.D., Chambers, P.A., James, W.F., Koch, E.W., Westlake, D.F., 2001. The interaction between water movement, sediment dynamics and submersed macrophytes. Hydrobiologia. https://doi.org/10.1023/A:1017520800568.

Martinez, J., Dabert, P., Barrington, S., Burton, C., 2009. Livestock waste treatment systems for environmental quality, food safety, and sustainability. Bioresour. Technol. 100, 5527-5536. https://doi.org/10.1016/j.biortech.2009.02.038.

Martins, L., Pereira, A., Oliveira, A., Fernandes, A., Sanches Fernandes, L.F., Pacheco, F. A.L., 2019. An assessment of groundwater contamination risk with radon based on clustering and structural models. Water 11, 1107. https://doi.org/10.3390/ w11051107. 
Masselink, R.J.H., Heckmann, T., Temme, A.J.A.M., Anders, N.S., Gooren, H.P.A., Keesstra, S.D., 2017. A network theory approach for a better understanding of overland flow connectivity. Hydrol. Process. 31, 207-220. https://doi.org/10.1002/ hyp.10993.

McGarigal, K., Marks, B., 1995. FRAGSTATS: Spatial pattern analysis program for quantifying landscape structure, Gerneral Technical Report PNW-GTR-351.

McKinney, W., 2015. Pandas - Powerful Python Data Analysis Toolkit. Pandas - Powerful Python Data Anal. Toolkit 1625.

Messina, N.J., Couture, R.M., Norton, S.A., Birkel, S.D., Amirbahman, A., 2020. Modeling response of water quality parameters to land-use and climate change in a temperate, mesotrophic lake. Sci. Total Environ. 713, 136549 https://doi.org/10.1016/j. scitotenv. 2020.136549.

Mishra, A., Alnahit, A., Campbell, B., 2020. Impact of land uses, drought, flood, wildfire, and cascading events on water quality and microbial communities: a review and analysis. J. Hydrol., 125707 https://doi.org/10.1016/j.jhydrol.2020.125707.

Mohamadi, M.A., Kavian, A., 2015. Effects of rainfall patterns on runoff and soil erosion in field plots. Int. Soil Water Conserv. Res. https://doi.org/10.1016/j. iswcr.2015.10.001.

Morley, S.A., Karr, J.R., 2002. Assessing and restoring the health of urban streams in the Puget Sound Basin. Conserv. Biol. https://doi.org/10.1046/j.1523-1739.2002.010 67.x.

Morrice, J.A., Danz, N.P., Regal, R.R., Kelly, J.R., Niemi, G.J., Reavie, E.D., Hollenhorst, T., Axler, R.P., Trebitz, A.S., Cotter, A.M., Peterson, G.S., 2008. Human influences on water quality in Great Lakes coastal wetlands. Environ. Manag. 41, 347-357. https://doi.org/10.1007/s00267-007-9055-5.

Ni, X., Parajuli, P.B., Ouyang, Y., Dash, P., Siegert, C., 2021. Assessing land use change impact on stream discharge and stream water quality in an agricultural watershed. Catena 198, 105055. https://doi.org/10.1016/j.catena.2020.105055.

Nilsson, C., Svedmark, M., 2002. Basic principles and ecological consequences of changing water regimes: Riparian plant communities. Environ. Manage. https://doi. org/10.1007/s00267-002-2735-2.

Nobre, R.L.G., Caliman, A., Cabral, C.R., Araújo, F., de, C., Guérin, J., Dantas, F., da, C.C., Quesado, L.B., Venticinque, E.M., Guariento, R.D., Amado, A.M., Kelly, P., Vanni, M. J., Carneiro, L.S., 2020. Precipitation, landscape properties and land use interactively affect water quality of tropical freshwaters. Sci. Total Environ. 716, 137044 https://doi.org/10.1016/j.scitotenv.2020.137044.

Pak, H.Y., Chuah, C.J., Yong, E.L., Snyder, S.A., 2021. Effects of land use configuration, seasonality and point source on water quality in a tropical watershed: a case study of the Johor River Basin. Sci. Total Environ. 780, 146661 https://doi.org/10.1016/j. scitotenv.2021.146661.

Pascoal, C., Cássio, F., Marcotegui, A., Sanz, B., Gomes, P., 2005a. Role of fungi, bacteria, and invertebrates in leaf litter breakdown in a polluted river. J. North Am. Benthol. Soc. https://doi.org/10.1899/05-010.1.

Pascoal, C., Pinho, M., Cássio, F., Gomes, P., 2003. Assessing structural and functional ecosystem condition using leaf breakdown: Studies on a polluted river. Freshw. Biol. https://doi.org/10.1046/j.1365-2427.2003.01130.x.

Pascoal, C., Marvanová, L., Cássio, F., 2005b. Aquatic hyphomycete diversity in streams of Northwest Portugal. Fungal Divers 19, 109-128. https://doi.org/10.1007/ s00442-005-0300-4.

Peixoto, F.P., Carrola, J., Coimbra, A.M., Fernandes, C., Teixeira, P., Coelho, L., Conceição, I., Oliveira, M.M., Fontaínhas-Fernandes, A., 2013. Oxidative stress responses and histological hepatic alterations in barbel, Barbus bocagei, from Vizela River, Portugal. Rev. Int. Contam. Ambient. 29, 29-38.

Pissarra, T.C.T., Valera, C.A., Costa, R.C.A., Siqueira, H.E., Martins Filho, M.V., Valle Júnior, R.F., do, Sanches Fernandes, L.F., Pacheco, F.A.L., 2019. A regression mode of stream water quality based on interactions between landscape composition and riparian buffer width in small catchments. Water 11, 1757. https://doi.org/ $10.3390 /$ w11091757.

Potter, K.M., Cubbage, F.W., Schaberg, R.H., 2005. Multiple-scale landscape predictors of benthic macroinvertebrate community structure in North Carolina. Landsc. Urban Plan. 71, 77-90. https://doi.org/10.1016/J.LANDURBPLAN.2004.02.001.

Ramião, J.P., Cássio, F., Pascoal, C., 2020. Riparian land use and stream habitat regulate water quality. Limnologica 82, 125762. https://doi.org/10.1016/j. limno.2020.125762.

Rebekić, A., Lončarić, Z., Petrović, S., Marić, S., 2015. Pearson's or Spearman's correlation coefficient - which one to use? Poljoprivreda 21, 47-54. https://doi.org/ 10.18047/poljo.21.2.8.

Reddy, Swarnkumar, Osborne, W.J., 2020. Heavy metal determination and aquatic toxicity evaluation of textile dyes and effluents using Artemia salina. Biocatal. Agric Biotechnol. 25 https://doi.org/10.1016/j.bcab.2020.101574.

Ribeiro, C.M.R., Maia, A.S., Ribeiro, A.R., Couto, C., Almeida, A.A., Santos, M., Tiritan, M.E., 2016. Anthropogenic pressure in a Portuguese river: Endocrine-disrupting compounds, trace elements and nutrients. J. Environ. Sci. Health - Part A Toxic/ Hazardous Subst. Environ. Eng. https://doi.org/10.1080/10934529.2016.1198622.

Rodrigues, V., Estrany, J., Ranzini, M., de Cicco, V., Martín-Benito, J.M.T., Hedo, J., Lucas-Borja, M.E., 2018. Effects of land use and seasonality on stream water quality in a small tropical catchment: the headwater of Córrego Água Limpa, São Paulo (Brazil). Sci. Total Environ. 622-623. https://doi.org/10.1016/j. scitotenv 2017.10.028.

Salgado Terêncio, D.P., Sanches Fernandes, L.F., Vitor Cortes, R.M., Moura, J.P., Leal Pacheco, F.A., Salgado Terêncio, D.P., Sanches Fernandes, L.F., Vitor Cortes, R.M., Moura, J.P., Leal Pacheco, F.A., 2019. Can land cover changes mitigate large floods? a reflection based on partial least squares-path modeling. Water 11,684 . https://doi. $\operatorname{org} / 10.3390 /$ w11040684.

Santos, R.M.B., Sanches Fernandes, L.F., Pereira, M.G., Cortes, R.M.V., Pacheco, F.A.L., 2015a. A framework model for investigating the export of phosphorus to surface waters in forested watersheds: implications to management. Sci. Total Environ. 536. https://doi.org/10.1016/j.scitotenv.2015.07.058.

Santos, R.M.B., Sanches Fernandes, L.F., Pereira, M.G., Cortes, R.M.V., Pacheco, F.A.L., 2015b. Water resources planning for a river basin with recurrent wildfires. Sci. Total Environ. 526, 1-13. https://doi.org/10.1016/j.scitotenv.2015.04.058.

Schiff, R., Benoit, G., 2007. Effects of impervious cover at multiple spatial scales on coastal watershed streams. J. Am. Water Resour. Assoc. https://doi.org/10.1111/j. 1752-1688.2007.00057.x.

Sharma, S.K., Sanghi, R., 2012. Advances in water treatment and pollution prevention, Advances in Water Treatment and Pollution Prevention. https://doi.org/10.100 7/978-94-007-4204-8.

Shehab, Z.N., Jamil, N.R., Aris, A.Z., Shafie, N.S., 2021. Spatial variation impact of landscape patterns and land use on water quality across an urbanized watershed in Bentong, Malaysia. Ecol. Indic. 122, 107254 https://doi.org/10.1016/j ecolind.2020.107254.

Shi, P., Zhang, Y., Li, Z., Li, P., Xu, G., 2017. Influence of land use and land cover patterns on seasonal water quality at multi-spatial scales. Catena 151, 182-190. https://doi. org/10.1016/J.CATENA.2016.12.017.

Sliva, L., Williams, D.D., 2001. Buffer zone versus whole catchment approaches to studying land use impact on river water quality. Water Res. https://doi. org/10.1016/S0043-1354(01)00062-8.

Soares, H.M.V.M., Boaventura, R.A.R., Machado, A.A.S.C., Esteves Da Silva, J.C.G., 1999. Sediments as monitors of heavy metal contamination in the Ave river basin (Portugal): multivariate analysis of data. Environ. Pollut. 105, 311-323. https://doi. org/10.1016/S0269-7491(99)00048-2.

Sousa, J.C.G., Ribeiro, A.R., Barbosa, M.O., Ribeiro, C., Tiritan, M.E., Pereira, M.F.R., Silva, A.M.T., 2019. Monitoring of the $17 \mathrm{EU}$ Watch List contaminants of emerging concern in the Ave and the Sousa Rivers. Sci. Total Environ. https://doi.org/10.10 16/j.scitotenv.2018.08.309.

Sousa, J.C.G., Barbosa, M.O., Ribeiro, A.R.L., Ratola, N., Pereira, M.F.R., Silva, A.M.T., 2020. Distribution of micropollutants in estuarine and sea water along the Portuguese coast. Mar. Pollut. Bull. 154, 111120 https://doi.org/10.1016/j marpolbul.2020.111120.

Sun, R., Chen, L., Chen, W., Ji, Y., 2013. Effect of land-use patterns on total nitrogen concentration in the upstream regions of the haihe river basin, China. Environ. Manage. https://doi.org/10.1007/s00267-011-9764-7.

Tabacchi, E., Lambs, L., Guilloy, H., Planty-Tabacchi, A.M., Muller, E., Décamps, H., 2000. Impacts of riparian vegetation on hydrological processes. Hydrol. Process. 14, 2959-2976. https://doi.org/10.1002/1099-1085(200011/12)14:16/17<2959::AIDHYP129>3.0.CO;2-B.

Terêncio, D.P.S., Sanches Fernandes, L.F., Cortes, R.M.V., Pacheco, F.A.L., 2017. Improved framework model to allocate optimal rainwater harvesting sites in small watersheds for agro-forestry uses. J. Hydrol. 550, 318-330. https://doi.org/ 10.1016/j.jhydrol.2017.05.003.

Tolessa, T., Senbeta, F., Kidane, M., 2016. Landscape composition and configuration in the central highlands of Ethiopia. Ecol. Evol. 6, 7409-7421. https://doi.org/ 10.1002/ece3.2477.

Tran, C.P., Bode, R.W., Smith, A.J., Kleppel, G.S., 2010. Land-use proximity as a basis for assessing stream water quality in New York State (USA). Ecol. Indic. https://doi.org/ 10.1016/j.ecolind.2009.12.002.

Tran, N.H., Reinhard, M., Khan, E., Chen, H., Nguyen, V.T., Li, Y., Goh, S.G., Nguyen, Q. B., Saeidi, N., Gin, K.Y.H., 2019. Emerging contaminants in wastewater, stormwater runoff, and surface water: application as chemical markers for diffuse sources. Sci. Total Environ. 676, 252-267. https://doi.org/10.1016/j.scitotenv.2019.04.160.

Uuemaa, E., Roosaare, J., Mander, Ü., 2005. Scale dependence of landscape metrics and their indicatory value for nutrient and organic matter losses from catchments. Ecol. Indic. https://doi.org/10.1016/j.ecolind.2005.03.009.

Uuemaa, E., Roosaare, J., Mander, Ü., 2007. Landscape metrics as indicators of river water quality at catchment scale. Nord. Hydrol. 38, 125-138. https://doi.org/ 10.2166/nh.2007.002.

Vannote, R.L., Minshall, G.W., Cummins, K.W., Sedell, J.R., Cushing, C.E., 1980. The river continuum concept. Can. J. Fish. Aquat. Sci. 37, 130-137. https://doi.org/10. 1139/f80-017.

Wan, R., Cai, S., Li, H., Yang, G., Li, Z., Nie, X., 2014. Inferring land use and land cover impact on stream water quality using a Bayesian hierarchical modeling approach in the Xitiaoxi River Watershed, China. J. Environ. Manag. 133, 1-11. https://doi.org/ 10.1016/j.jenvman.2013.11.035.

Wang, M., Duan, L., Wang, J., Peng, J., Zheng, B., 2020. Determining the width of lake riparian buffer zones for improving water quality base on adjustment of land use structure. Ecol. Eng. 158, 106001 https://doi.org/10.1016/j.ecoleng.2020.106001.

Wei, W., Gao, Y., Huang, J., Gao, J., 2020. Exploring the effect of basin land degradation on lake and reservoir water quality in China. J. Clean. Prod. 268, 122249 https:// doi.org/10.1016/j.jclepro.2020.122249.

White, M.D., Greer, K.A., 2006. The effects of watershed urbanisation on the stream hydrology and riparian vegetation of Los Peñasquitos Creek, California. Landsc. Urban Plan. https://doi.org/10.1016/j.landurbplan.2004.11.015.

Wiek, A., Larson, K.L., 2012. Water, People, and Sustainability-A Systems Framework for Analysing and Assessing Water Governance Regimes. Water Resour. Manag. htt ps://doi.org/10.1007/s11269-012-0065-6.

Wilson, C., Weng, Q., 2010. Assessing surface water quality and its relation with urban land cover changes in the Lake Calumet Area, Greater Chicago. Environ. Manag. 45, 1096-1111. https://doi.org/10.1007/s00267-010-9482-6.

Wu, J., Shen, W., Sun, W., Tueller, P.T., 2002. Empirical patterns of the effects of changing scale on landscape metrics. Landsc. Ecol. https://doi.org/10.1023/A:1022 995922992. 
Yan, F., Kang, Q., Wang, S., Wu, S., Qian, B., 2021. Improved grey water footprint mode of noncarcinogenic heavy metals in mine wastewater. J. Clean. Prod. 284, 125340 https://doi.org/10.1016/j.jclepro.2020.125340.

Ye, Y., He, X.Y., Chen, W., Yao, J., Yu, S., Jia, L., 2014. Seasonal water quality upstream of Dahuofang Reservoir, China - the effects of land use type at various spatial scales. Clean - Soil, Air, Water. https://doi.org/10.1002/clen.201300600.

Yong, S.T.Y., Chen, W., 2002. Modeling the relationship between land use and surface water quality. J. Environ. Manage. https://doi.org/10.1006/jema.2002.0593.

Yu, S., Xu, Z., Wu, W., Zuo, D., 2016. Effect of land use types on stream water quality under seasonal variation and topographic characteristics in the Wei River basin, China. Ecol. Indic. 60, 202-212. https://doi.org/10.1016/J.ECOLIND.2015.06.029.

Zar, J.H., 2005. Spearman Rank Correlation. Encycl. Biostat. https://doi.org/10.1002/ 0470011815.b2a15150.

Zhang, J., Li, S., Dong, R., Jiang, C., Ni, M., 2019. Influences of land use metrics at multispatial scales on seasonal water quality: A case study of river systems in the Three
Gorges Reservoir Area, China. J. Clean. Prod. 206, 76-85. https://doi.org/10.1016/ J.JCLEPRO.2018.09.179.

Zhang, J., Li, S., Jiang, C., 2020. Effects of land use on water quality in a river basin (daning) of the three gorges reservoir area, China: Watershed versus riparian zone. Ecol. Indic. 113, 106226 https://doi.org/10.1016/j.ecolind.2020.106226.

Zhang, X., Liu, Y., Zhou, L., 2018. Correlation analysis between landscape metrics and water quality under multiple scales. Int. J. Environ. Res. Public Health 15. https:// doi.org/10.3390/ijerph15081606.

Zhang, Y., Li, F., Zhang, Q., Li, J., Liu, Q., 2014. Tracing nitrate pollution sources and transformation in surface- and ground-waters using environmental isotopes. Sci. Total Environ. 490, 213-222. https://doi.org/10.1016/j.scitotenv.2014.05.004.

Zhao, J., Yang, K., Tai, J., Shan, F., 2011. Review of the relationship between regional landscape pattern and surface water quality. Shengtai Xuebao/ Acta Ecol. Sin.

Zörb, C., Senbayram, M., Peiter, E., 2014. Potassium in agriculture-status and perspectives. J. Plant Physiol. https://doi.org/10.1016/j.jplph.2013.08.008. 